\title{
THERMOCHEMICAL ENERGY STORAGE OF CONCENTRATED SOLAR POWER BY \\ INTEGRATION OF THE CALCIUM LOOPING PROCESS AND A $\mathrm{CO}_{2}$ POWER CYCLE
}

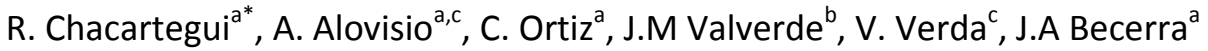 \\ ${ }^{a}$ Energy Engineering Department, University of Seville, Camino de los Descubrimientos s/n, 41092 Sevilla, Spain \\ ${ }^{b}$ Faculty of Physics, University of Seville, Avenida Reina Mercedes s/n, 41012 Sevilla, Spain \\ 'Politecnico di Torino, Department of Energy Engineering, Corso Duca degli Abruzzi 24, 10129 Torino, Italy \\ *Corresponding author. Tel.: +34 9544872 42; E-mail address: ricardoch@us.es
}

\section{Abstract}

Energy storage is the main challenge for a deep penetration of renewable energies into the grid to overcome their intrinsic variability. Thus, the commercial expansion of renewable energy, particularly wind and solar, at large scale depends crucially on the development of cheap, efficient and non-toxic energy storage systems enabling to supply more flexibility to the grid. The Ca-Looping (CaL) process, based upon the reversible carbonation/calcination of $\mathrm{CaO}$, is one of the most promising technologies for thermochemical energy storage (TCES), which offers a high potential for the long-term storage of energy with relatively small storage volume. This manuscript explores the use of the CaL process to store Concentrated Solar Power (CSP). A CSP-CaL integration scheme is proposed mainly characterized by the use of a $\mathrm{CO}_{2}$ closed loop for the CaL cycle and power production, which provides heat decoupled from the solar source and temperatures well above the $\sim 550 \circ \mathrm{C}$ limit that poses the use of molten salts currently used to store energy as sensible heat. The proposed CSP-CaL integration leads to high values of plant global efficiency (of around 45-46\%) with a storage capacity that allows for long time gaps between load and discharge. Moreover, the use of environmentally benign, abundantly available and cheap raw materials such as natural limestone would mark a milestone on the road towards the industrial competitiveness of CSP.

Keywords: Energy Storage, Calcium looping (CaL), Concentrated Solar Power (CSP), $\mathrm{CO}_{2}$, Thermochemical Energy Storage (TCES) 


\section{Introduction}

Efficient and affordable energy storage systems are urgently needed in order to cope with the intrinsic variability of renewable energy sources, which would allow a deep penetration of renewable energy power generation into the grid. In particular, Concentrated Solar Power (CSP) lends itself for the storage of heat as a primary form of energy that could be used for electricity generation on demand. In recent years, a number of thermal storage technologies for medium to high temperature CSP systems have been developed from the use of materials in which energy is stored as sensible heat [1-3]. Diverse materials with high heat capacity are employed in thermal energy storage (TES) systems such as water [4], molten salts [5-7], mineral oils [8] or ceramic materials [9]. Commercial plants of considerable size $(>100 \mathrm{MWt})$ do already exist where heat is stored in molten salts and used overnight to generate electricity. Another type of storage under investigation is based on the latent heat stored in some materials when they experience a change of phase [10-12]. Phase change materials (PCM) allow attaining higher storage capacities as compared to storage as sensible heat [13]. Nevertheless, both sensible and latent heat storage forms suffer from unavoidable energy losses and other issues, which hinder their industrial competitiveness in the short-medium term.

A third possibility to store CSP, currently under research and development, is the thermochemical energy storage (TCES) $[14,15]$. TCES consists of using the heat obtained from an external source to drive an endothermic reaction. When energy is needed, the separately stored products of the reaction are brought together at the necessary conditions for the reverse exothermic reaction to occur, which releases the previously used heat for power production. The main advantages of TCES as compared to TES and PCMs are a considerably higher energy density as well as the possibility of storing energy in the long term $[1,14]$. 
Moreover, in addition to the chemically stored heat, the products of the reaction can be also employed to store sensible heat.

Table 1: Energy density and turning temperature of various thermochemical energy storage systems. Adapted from [16].

Among the diverse possibilities explored for TCES at large scale, one of the most promising technologies is the Calcium Looping (CaL) process, which relies on the calcination-carbonation reaction of $\mathrm{CaCO}_{3}$ (Eq. (1)) [17-19]:

$$
\mathrm{CaCO}_{3(\mathrm{~s})}
$$

As can be seen in Table 1

The CaL process begins with the decomposition of $\mathrm{CaCO}_{3}$ in the calcination reactor (calciner) yielding $\mathrm{CaO}$ and $\mathrm{CO}_{2}$ as reaction byproducts. A high energy input is necessary to increase the input stream temperature up to the value required for the endothermic calcination reaction to occur at a sufficiently fast rate, which is essentially determined by the composition of the gas 
in the calcination environment $[24,25]$. Once sensible heat from the $\mathrm{CaO}$ and $\mathrm{CO}_{2}$ streams at the calciner outlet is recovered, these products are stored at ambient temperature for their use afterwards as a function of demand. Storage of the products could be prolonged to weeks or even months as depending on storage conditions and energy demand [1]. Once needed, the reactants are circulated into a carbonator reactor, where the energy stored in chemical form is released through the reverse reaction (carbonation). Efficient gas-solid contact and heat/mass transfer in the calciner and carbonator reactors could be ensured by the use of circulating fluidized-beds (CFB), which are operated under the fast fluidization regime with gas velocities of the order of $5-10 \mathrm{~m} / \mathrm{s}[26,27]$. An advantage of this technology ahead of its incorporation into the market is the proven efficiency and durability of such type of fluidized bed reactors.

The CaL process has been widely studied in recent years but mainly for its application to capture $\mathrm{CO}_{2}$ in fossil fuel power plants [28]. The standard cycle for $\mathrm{CO}_{2}$ capture from flue gas streams uses lime $(\mathrm{CaO})$, which can be derived from limestone calcination, to produce $\mathrm{CaCO}_{3}$ by quick carbonation at high temperature $\left(\sim 650^{\circ} \mathrm{C}\right)$. Once $\mathrm{CO}_{2}$ is captured in the carbonator and heat from the exothermic reaction is recovered, the almost $\mathrm{CO}_{2}$ free flue gas is released into the atmosphere. Several carbonator reactor models have been developed to predict the $\mathrm{CO}_{2}$ capture efficiency as depending on operating conditions and $\mathrm{CaO}$ multicycle conversion under $\mathrm{CaL}$ conditions for $\mathrm{CO}_{2}$ capture [29-31]. These involve carbonation under relatively low $\mathrm{CO}_{2}$ partial pressure (about $0.15 \mathrm{~atm}$ ) and calcination at very high temperatures (around 950 - $\mathrm{C}$ ) under high $\mathrm{CO}_{2}$ partial pressure with short residence times at both stages. Under these conditions, limestone derived $\mathrm{CaO}$ exhibits a severe drop of conversion in only a few cycles converging towards a residual value of just about 0.07 , which makes it necessary to periodically purge the poorly active sorbent and replace it by a makeup flow of fresh limestone. The efficiency of the calciner reactor and the energy penalty efficiency caused by the CaL integration $[32,33]$ into coal fired power plants (CFPP) have been also important subjects of analysis [25,34-36]. Pilot plants (of size on the order of 1-2 MWth) demonstrate 
the achievement of $\mathrm{CO}_{2}$ capture efficiencies around $90 \%[37,38]$ whereas model simulations predict an efficiency penalty on power generation around $5-6 \%$ when scaling up the technology to a commercial level [39].

The present manuscript is focused on the development of an integration model to use the CaL process for TCES in CSP plants. Integration models aimed at similar goals have been already analyzed by other authors. Tregambi et al. [40] proposed a scheme whereby calcination in the CaL process is assisted by CSP for $\mathrm{CO}_{2}$ capture in a coal fired power plant. Edwards et al. [18] studied a CSP-CaL system in which the heat produced in the carbonator reactor is used for power generation through a $\mathrm{CO}_{2} /$ air open cycle. Remarkably, results from this work indicate that the global plant efficiency would be hampered by a too high CaO reactivity. Nevertheless, a high $\mathrm{CaO}$ reactivity leads to a decrease of the fraction of unreacted $\mathrm{CaO}$ in the circulating stream of solids thereby allowing for a reduction of the energy penalty. This suggests that the performance of the CSP-CaL integration could be further improved by optimizing the heat recovery exchanger network as will be shown in the present work.

In this manuscript, a novel CSP-CaL integration model is explored from coupling the CaL process to a closed $\mathrm{CO}_{2}$ power system. Full integration is optimized by means of the pinchanalysis methodology. A global layout is derived and the effects of main parameters on the global cycle performance are studied by a sensitivity analysis. The obtained results demonstrate that a global thermal efficiency above $45 \%$ may be attained, which makes the proposed integration model a highly competitive option for TCES. The use of an abundantly available and cheap $\mathrm{CaO}$ precursor such as limestone allows achieving the goal of decoupling the storage and delivery periods at low cost, and the process may be carried out with already existing mature technologies to further reduce costs. In the rest of the manuscript, the proposed CSP-CaL integration model is described after which the effects of parameters 
critically intervening on the cycle are discussed. Finally, a sensitivity analysis of the model response to the variation of main inputs is carried out.

\section{CSP-CaL energy storage system}

This section is devoted to describe the model developed for the analysis and optimization of the CSP-CaL integration (Engineering Equation Solver Professional software has been used to this end). The integration is built upon models of the different components that play a main role on the technology such as the carbonator reactor, solid streams, heat exchangers, solid reservoirs, $\mathrm{CO}_{2}$ storage tank, turbines and compressors.

\subsection{Description of the CSP-CaL integration}

A major benefit of the CSP-CaL integration is that it makes use of natural limestone as $\mathrm{CaO}$ precursor. Limestone is an abundant, non-toxic and non-corrosive cheap material ( $10 \$ /$ ton), which is geographically widespread and has adequate physical properties in the desired temperature range for CSP energy storage. As usually reported in the last years by studies on the use of the $\mathrm{CaL}$ process for $\mathrm{CO}_{2}$ capture, limestone derived $\mathrm{CaO}$ shows a marked deactivation under the standard $\mathrm{CaL}$ conditions specific for $\mathrm{CO}_{2}$ capture $[34,41,42]$ that necessarily involve calcination at rather high temperatures $(\sim 950 \circ \mathrm{C})$ under high $\mathrm{CO}_{2}$ partial pressure and carbonation under low $\mathrm{CO}_{2}$ partial pressure [28]. Thus, it is usually assumed that a marked drop of $\mathrm{CaO}$ conversion will also hinder the efficiency of the CaL process for TCES [43]. However, it is important to remark that the multicycle conversion of $\mathrm{CaO}$ under calcination/carbonation conditions that optimize the efficiency of the CSP-CaL integration (radically different from those specific for $\mathrm{CO}_{2}$ capture as will be seen) could be kept at a stable and high value. This has been confirmed by a recent thermogravimetric analysis study whose results will be summarized in section 3.5 [44]. 
Figure 1 shows a schematic representation of the proposed CSP-CaL integration. The central idea behind this scheme is to separate the heat storage and power generation phases. Heat storage takes place in the solar receiver, where the calcination reaction of $\mathrm{CaCO}_{3}$ occurs at expense of solar energy. Calcination can be performed in a solar reactor, most likely a central tower receiver. A number of solar calciner prototypes have been already developed based on fluidized beds $[45,46]$, rotary kilns $[47,48]$ and cyclone atmospheric reactors [49]. A potentially cheap and simple option consists of falling particle receivers [50]. Since the CSP-CaL integration scheme proposed in the present work relies on a closed $\mathrm{CO}_{2}$ cycle, a pure $\mathrm{CO}_{2}$ stream must be retrieved as output from the calciner. Two options are feasible to this end: i) performing calcination under a $100 \% \mathrm{CO}_{2}$ atmosphere or $\mathrm{ii}$ ) under an easily separable gas from $\mathrm{CO}_{2}$. The first choice would make it necessary to operate the calciner under low absolute pressure in order to reduce the calcination temperature and to avoid hampering the reactivity of the regenerated $\mathrm{CaO}$ due to excessive sintering as observed when calcination is carried out under high $\mathrm{CO}_{2}$ partial pressure for $\mathrm{CO}_{2}$ capture [51]. In regards to the second option, calcination could be carried out under superheated steam, which can be separated from the released $\mathrm{CO}_{2}$ by condensation. Calcination under superheated steam can be carried out by means of a flash calcination process, whereby limestone particles are quickly calcined in an entrained-flow reactor at short residence times [14] [52]. Moreover, calcination under superheated steam further enhances the $\mathrm{CaCO}_{3}$ decomposition rate and considerably decreases the required temperature to attain complete calcination down to $700-750 \circ \mathrm{C}[53,54]$. Calcination under superheated steam in flash calciners is completed in seconds, compared to hours in rotary and shaft kilns [54]. Achieving fast calcination at a moderate temperature would be highly beneficial for the integration of the CaL technology in CSP tower plants. It would allow using mature and inexpensive solar receivers capable of heating the working gas at temperatures up to $800^{\circ} \mathrm{C}$ based on metal alloys instead of ceramic materials currently under development that would be needed to achieve higher temperatures [55]. The use of superheated steam for 
calcination in the solar reactor would be also facilitated by the possibility of in-situ direct generation of superheated steam in solar receivers. Another gas that could be employed for calcination is Helium, which is easily separable from $\mathrm{CO}_{2}$ by means of membranes and has a catalyzing effect similar to superheated steam due to its high thermal conductivity and the high diffusivity of the released $\mathrm{CO}_{2}[53]$.

Figure 1: Schematic representation of the CSP-CaL integration model with values of temperature, pressure, mass flow rate and composition in key stages (a $100 \mathrm{MW}_{\text {th }}$ CSP tower plant is considered).

Coming back to the integration scheme (Figure 1), and once calcination takes place using concentrated solar power, the released $\mathrm{CO}_{2}$ is sent to a storage tank after being cooled and compressed whereas the $\mathrm{CaO}$ stream is transported to the storage solids reservoir after being brought near to ambient conditions. The solids stream entering into the calciner, and consisting of $\mathrm{CaCO}_{3}$ and unreacted $\mathrm{CaO}$, is preheated in two exchangers ( $\mathrm{HXA}$ and $\mathrm{HXB}$ as detailed in Figure 1) using the sensible heat released by the hot streams leaving the calciner. Thus, the total solar energy entering into the system is used to heat the reactants and to drive the endothermic chemical reaction, which serves to store the solar energy as both sensible and chemical and form.

The energy discharge phase takes place in the carbonator, which is a pressurized fluidized bed reactor wherein the carbonation reaction takes place under pure $\mathrm{CO}_{2}$ at the highest possible temperature in order to achieve a high thermal to electric efficiency. Pressurized carbonation provides a great range of possibilities and thermal applications for a direct integration with a power cycle, and could enhance the long term $\mathrm{CaO}$ reactivity in the CaL process [56]. The heat of the carbonation reaction is delivered to a gas turbine by means of the $\mathrm{CO}_{2}$ as carrier and through a Joule-Brayton cycle, which implies a direct integration between heat released and power cycle. Another possibility could be to implement an indirect integration through a heat exchanger that can be coupled with an externally heated power block (steam turbine, Stirling, Supercritical $\mathrm{CO}_{2}\left(\mathrm{SCO}_{2}\right)$, etc.). The proposed $\mathrm{CO}_{2}$ power cycle is a closed and regenerative 
cycle, whereby the heat removed by the reactants in the carbonator is recovered in an open cyclone exchanger (HXF in Figure 1). Thus, in this heat exchanger (HXF) heat from the exhaust $\mathrm{CO}_{2}$ stream serves to heat up the $\mathrm{CaO}$ solids before entering into the carbonator while in HXE the residual heat from the solids at the carbonator output is extracted to pre-heat the $\mathrm{CO}_{2}$ stream at the carbonator inlet. Part of the power needed in the compression stage of the Joule-Brayton cycle is provided by the expansion of the pressurized $\mathrm{CO}_{2}$ used for reaction in the carbonator. Expansion of stored $\mathrm{CO}_{2}$ yields useful work while, at the same time, provides efficiently cooling power by expanding to low temperatures (up to $-30^{\circ} \mathrm{C}$ to be used for $\mathrm{CO}_{2}$ intercooling compression of the stream coming from the carbonator). On the other side, $\mathrm{CO}_{2}$ may fall under the saturation curve while expanding, thereby some form of heat supply before and during expansion is needed to protect the turbine blades. For these reasons, C1 and T2 (see Figure 1) are thermally coupled to avoid the use of massive air cooling devices and to further reduce costs. A possible thermal coupling scheme between $\mathrm{C} 1$ and $\mathrm{T} 2$ is detailed in Figure 2.

Figure 2: Possible thermal coupling scheme between $\mathrm{C} 1$ and $\mathrm{T} 2$ (see Fig. 1) by means of an external IC+RH exchanger. $\mathrm{RH}$ : initial pre-heating to $50^{\circ} \mathrm{C}(1-2)$ and multistage expansion with reheating stages up to $40^{\circ} \mathrm{C}$. IC: cooling up to $30^{\circ} \mathrm{C}$. a) Schematics b) Composite curves c) Processes on the PH diagram.

Concerning C2, due to the high compression ratios (about 100:1), intercooling compression is needed in order to lower down the power penalty. Sensible heat available between the compression end temperature at each stage and the dead state is recovered. The possibility of recovering waste $\mathrm{CO}_{2}$ compression heat has been investigated by means of pinch-analysis and minimum external energy requirement analysis techniques. As a main outcome, only a small fraction of waste compression heat (13-20\% depending on the number of stages) is recoverable. By increasing the number of intercooling stages the recovered heat turns to be 
less valuable while the compression work is reduced thus resulting in increased efficiency. If more than 5 intercooling stages are performed, the inclusion of additional waste heat exchangers yields negligible efficiency gain. Thus, the optimum solution as regards cost, efficiency and technical feasibility is to carry out intercooling compression up to supercritical pressure and then cooling to near ambient temperature by means of simple water/air coolers without heat recovery.

Solids conveying can be carried out by means of the mature pneumatic technology that guarantees rapid transport of granular solids, routing flexibility, as well as the possibility of streams splitting, and it is suitable to successfully convey high temperature materials. Calcium based powders are easily conveyable in the dense phase involving low gas velocity in a nonsuspension mode. The very high solids loading ratios (defined as the ratio between material and pneumatic gas mass flow rate) associated with dense phase conveying (around 45 for cement powders [57]) imply relatively low conveying energy consumption (around 3-5 $\mathrm{MJ}$ ton $1 / 100 \mathrm{~m}[57])$ and a limited heat exchange between the conveying gas and conveyed particles that has been dismissed in the model.

In order to achieve higher integration efficiency an optimized heat exchanger network is necessary. In the model, heat exchangers are characterized by a single parameter, namely their minimum temperature difference. Countercurrent flow is assumed in each exchanger. Gas-solid heat exchange can be performed in both open (direct contact) or closed configuration. Open configurations have been experimentally demonstrated to be effective, reaching approach temperatures of $15^{\circ} \mathrm{C}$ by means of axial flow cyclones operating in a close to counter-flow mode [58]. There exist several closed gas-solid exchangers operating in counter-flow mode commercially available. A favorable choice for our purpose would consist of a series of vertical plates, across which bulk solids slowly flow downwards by gravity exchanging heat by conduction with a fluid circulating inside the plates [59]. This mature 
technology is characterized by low energy consumption and is almost maintenance-free as it does not include any moving parts. Solid-solid heat exchange can be pursued in practice by adapting conveniently this technology and using one or more intermediate heat-transfer fluids recirculated within the bulk of both solids by means of a small pumping device.

\subsubsection{Mass balance}

Figure 3 shows a schematic representation of the mass streams circulating in the loop.

\section{Figure 3: Mass-balance schematics of the plant showing the flow rates of solids and $\mathrm{CO}_{2}$ streams between the carbonator and calciner.}

As can be seen in Figure 3, a fraction $F_{C a O, c r b}$ of the total sorbent recirculating flow rate $\left(F_{R, c r b}\right)$ fully reacts in the carbonator, which yields an equal molar flow rate of carbonated solids $\mathrm{F}_{\mathrm{CaCO}_{3}, \mathrm{Crb}}$ while the remaining flow rate is assumed to persist as unreacted $\mathrm{CaO}$

$\left(F_{C a O, u n r, c r b}\right)$. Their sum gives at the outlet a solid molar rate $F_{R, c r b}$. In the model, $F_{\mathrm{CaCO}_{3,}, \mathrm{crb}}$ and $F_{C a O, u n r, c r b}$ are considered as two distinct streams, although the powder in reality consists of partially carbonated particles in which a core of unreacted $\mathrm{CaO}$ is surrounded by a layer of $\mathrm{CaCO}_{3}$. The average $\mathrm{CaO}$ conversion $X$ is a fundamental parameter to quantify the amount of $\mathrm{CaO}$ converted to $\mathrm{CaCO}_{3}$ in the calciner, i.e. the amount of $\mathrm{CaCO}_{3}$ produced $\left(X=F_{\mathrm{CaCO}_{3}} / F_{R}\right)$. Thus, small values of $\mathrm{CaO}$ conversion $X$ lead to the requirement of large amounts of unreacted sorbent recirculating in the loop to keep constant the $\mathrm{CaCO}_{3}$ production.

In the calciner, the partially carbonated particles are assumed to experience complete decomposition, thus each mole of $\mathrm{CaCO}_{3}\left(F_{\mathrm{CaCO}_{3, \mathrm{clc}}}\right)$ gives rise to a mole of $\mathrm{CO}_{2}\left(F_{\mathrm{CO}_{2}, \text { clc, out }}\right)$ and a mole of regenerated sorbent $\left(F_{\mathrm{CaO}, \mathrm{clc}}\right)$. The molar flow rate at the calciner output is therefore the sum of two streams: a solid stream of $\mathrm{CaO}$ composed of both regenerated and unreacted sorbent and a gaseous stream $\left(F_{\mathrm{CO}_{2}, \text { clc,out }}\right)$ of $\mathrm{CO}_{2}$. 
As shown in Figure 3, the molar rate of $\mathrm{CO}_{2}$ flowing into the carbonator is well above the reacting molar rate, which is given by $E_{e q} F_{C O_{2}, c r b, i n}$. Here, $E_{e q}$ is the equilibrium $\mathrm{CO}_{2}$ reaction efficiency (to be defined in eq. (9)). The excess $\mathrm{CO}_{2}\left(F_{\mathrm{CO}_{2}, \mathrm{~S}}\right)$ is thus used to remove the heat of carbonation and is looped through the closed power cycle for the generation of electricity.

The molar flows circulating in the two regions of the plant are decoupled. While the solar calciner can work only in presence of solar power (daytime and clear sky conditions), power demand in the carbonator side must be satisfied over a $24 \mathrm{~h}$ period. Storage vessels must be thus sized to provide buffer storage to allow the carbonator/turbine group supplying electricity demand over $24 \mathrm{~h}$ by adjusting the load as needed. Concerning the $\mathrm{CO}_{2}$ storage volume (Figure 4), a minimum pressure of 75 bar is needed in order to guarantee supercritical $\mathrm{CO}_{2}$ storage conditions (considering storage at ambient temperature). As can be seen in Figure 4, at lower storage pressures, it would be necessary to liquefy the $\mathrm{CO}_{2}$ (with the consequent energy penalization) in order to avoid unreasonably large storage volumes. The proportional size of storage tanks can be achieved by integrating several commercially available tanks. They would use a reduced area compared to the large surface area available in the associated tower CSP plant. Higher $\mathrm{CO}_{2}$ storage pressures can be considered but, in this case, the cycle efficiency could be lower as can be seen below in Figure 19.

Figure 4: $\mathrm{CO}_{2}$ storage conditions by considering a $12 \mathrm{~h}$ daytime (100 $\mathrm{MW}_{\mathrm{th}} \mathrm{CSP}$ plant).

In order to guarantee steady-state operation, the following mass-balance must be satisfied:

$$
\int_{24 h} F_{C a C O 3, c l c}(t) d t=\int_{24 h} F_{C a C O 3, c r b}(t) d t
$$

In the present model, the plant performance is determined as an average over a $24 \mathrm{~h}$ period, in which the molar flows are considered as constant and equal to the integral average value over the daytime curve. Accordingly, an average daytime period $\Delta t_{\text {sun }}$ is considered, in which the 
sun-solar concentrators provide sufficient energy to run the decomposition reaction in the calciner. In this way, it is possible to derive an averaged ratio between the circulating flow rates in the calciner and carbonator sides of the plant:

$$
\overline{F_{\mathrm{CaCO}_{3}, \mathrm{Clc}}} \cdot \Delta t_{\text {sun }}=\overline{F_{\mathrm{CaCO}_{3}, \mathrm{crb}}} \cdot 24
$$

If, for instance, we consider a daytime $\Delta t_{\text {sun }}$ of $8 \mathrm{~h}$ (clear sky), the ratio between the circulating streams in the calciner and the carbonator will be of 3 over the 24 hours, while in case that the daytime is $12 \mathrm{~h}$, the molar flow rates in the calciner side will be twice those in the carbonator side. A more sophisticated model (dynamic model) would be necessary in a framework of longperiod control taking into account real data for solar energy input in order to obtain real energy production values along the year. Nevertheless, the scope of this paper is just to estimate the cycle efficiency for a fixed irradiation. A variation in the solar input power (as a function of solar irradiance) modifies mass and energy flows in the cycle, which requires improving the control strategy to maximize the cycle performance, including part-load strategies for the closed Brayton cycle.

\subsubsection{Energy balance}

The first thermodynamics law applied to a reacting system is used in both the carbonator and calciner reactors for the energy balance:

$$
\begin{gathered}
\sum_{i} F_{i, \text { out }} h_{i, \text { out }}-\sum_{i} F_{i, \text { in }} h_{i, \text { in }}=\Phi-\dot{W} \\
F_{i, \text { out }}-F_{i, \text { in }}=\xi v_{i}
\end{gathered}
$$

where $\xi$ denotes the extent of reaction per unit time. Arranging and considering that output conditions are reactor conditions, it is: 


$$
\xi \Delta H_{R}\left(T_{\text {react }}\right)+\sum_{i} F_{i, \text { in }}\left(h_{i, \text { react }}-h_{i, \text { in }}\right)=\Phi-\dot{W}
$$

with

$$
\Delta H_{R}\left(T_{\text {react }}\right)=\sum_{i} v_{i} h_{i, T}=\Delta H_{R}^{0}+\sum_{i} v_{i} \int_{\text {ref }}^{T_{\text {react }}} c_{p, i} d T
$$

being the reaction enthalpy change at the reaction temperature.

Energy change in the control volume consists therefore of the heat of reaction at the reactor temperature $\xi \Delta H_{R}\left(T_{\text {react }}\right)$ and the heat required to bring the reactants from inlet to reactor's conditions $\sum_{i} F_{i, \text { in }}\left(h_{i, \text { react }}-h_{i, \text { in }}\right)$.

Eq. (4), when applied to the carbonator, serves to balance out the amount of $\mathrm{CO}_{2}\left(\mathrm{~F}_{\mathrm{CO}_{2, S}}\right.$ in Fig. 3) needed to remove all the heat that is not absorbed by reactants or dispersed through the walls assuming isothermal conditions at the reactor. On the other hand, Eq. (4), when applied to the calciner, balances out the $\mathrm{CaCO}_{3}$ production in accordance with the net energy input of the system, which is the solar heat supply minus the heat losses occurring between the solar receiver and the reactor due to conduction, thermal radiation, absorption, etc.

\section{CSP-CaL energy storage cycle analysis}

The proposed cycle configuration is the result of an optimization analysis based on the pinchpoint method $[60,61]$. Thus, the heat exchanger network seeks for optimal internal heatrecovery performance in a broad range of operational conditions. In this section, the influence of the main cycle parameters are analyzed in order to determine the most efficient operating conditions. Table 2 shows several parameters used in the cycle simulations whose influence is discussed below. 
The proposed plant (Figure 1) is equipped with a solid-solid heat exchanger HXA, two indirect gas-solid heat exchangers (HXB and HXF), a gas-gas regenerator (HXG) and two cyclone gassolid direct heat exchangers (HXE and HXI).

\section{Table 2: Main simulation model data}

The results of the model for the proposed plant configuration will be reported as a function of the $\mathrm{CaO}$ conversion $X$, pressure ratio $P R$ in the $\mathrm{CO}_{2}$ turbine $\mathrm{T} 1$ (see Figure 1), absolute carbonator pressure $(P), \mathrm{T} 1$ turbine outlet pressure $(T O P)$, and carbonator temperature $(T)$, which have been identified as the key operational parameters.

\section{1 $\mathrm{CaO}$ conversion}

Conversion $(X)$ of the $\mathrm{CaO}$ solids population recycled in the loop plays a relevant role in the plant performance. Changes in the value of this parameter cause remarkable modifications in the necessary flow rates of the circulating solids, $\mathrm{CO}_{2}$ generation and $\mathrm{CaCO}_{3}$ consumption in the calciner, heat balance in the calciner and useful carbonation heat and storage size, which have a significant effect on the plant efficiency.

The results of the model simulations carried out demonstrate that the power balance in the calciner side is favored by high values of $X$ that allow decreasing the amounts of circulating solids, thus yielding lower heat-losses in the calciner side exchangers network and more heat available for calcination. $\mathrm{CaCO}_{3}$ decomposition and $\mathrm{CO}_{2}$ generation in the calciner are consequently enhanced and more heat is available in the discharge phase for carbonation. Carbonation heat is proportional to the amount of $\mathrm{CaO}$ and $\mathrm{CO}_{2}$ produced in the calciner and is partially absorbed by reactants and partially removed by the $\mathrm{CO}_{2}$ stream for power generation. For values of $\mathrm{CaO}$ conversion below a certain lower bound, the heat removed by inactive solids overcomes the heat of carbonation. In this situation, isothermal operation of the carbonator becomes compromised unless heat is provided by an external source. This critical value of 
conversion, $X_{\mathrm{lim}}$, is mainly dependent on the temperature of the inlet $\mathrm{CaO}$, which is in turn imposed by the temperature at main turbine output through HXF. This means that, in practice, the ratio of carbonator pressure to the T1 turbine outlet pressure $(P R)$ is the parameter that mainly determines the minimum value of $\mathrm{CaO}$ conversion needed for operation as will be seen ahead.

As can be observed in Figure 5, the higher $\mathrm{CaO}$ conversion the higher fraction of heat can be removed by the power fluid $\left(\mathrm{CO}_{2}\right.$ in the present case) given the lower flow rate of solids cycled within the system, which reduces the energy required in the form of sensible heat for the solids to reach the carbonation temperature. In the current cycle configuration, the presence of exchangers $\mathrm{HXG}$ and $\mathrm{HXI}$ ensure optimal thermal recovery and consequently the $\mathrm{CO}_{2}$ mass flow rate in the cycle is perfectly proportional to the carbonation heat (as may be seen in Figure 55).

Figure 5: Available heat of carbonation (left axis) and $\mathrm{CO}_{2}$ mass flow rate through the carbonator (right axis) vs $\mathrm{CaO}$ conversion

Figure 6a shows the thermal capacity rate (defined as the product of the molar flow rate by the specific heat of the fluid of interest $F c_{p}$ ) of the carbonator-side streams as a function of the $\mathrm{CaO}$ conversion. The cooling $\left(\mathrm{CO}_{2} \mathrm{C}\right)$ and preheating $\left(\mathrm{CO}_{2} \mathrm{p}\right) \mathrm{CO}_{2}$ streams' split ratios (see Fig. 1) are determined by means of a pinch-point optimization method.

When the amount of solids is reduced, a larger fraction of heat is regenerated in the heat exchanger HXG. This results in an increased size of the gas-gas regenerator HXG, unlike for HXF and $\mathrm{HXI}$. High values of $\mathrm{CO}_{2}$ molar flow rates for low pressure ratios $P R$ can push up too much the size of the exchanger HXG. For this reason, too low $P R$ values should be avoided.

Figure 6: a) Thermal capacity of streams $\left(\mathrm{CaO}, \mathrm{CaCO}_{3}\right.$, and $\left.\mathrm{CO}_{2}\right)$ in the carbonator side heat exchangers (HXE, HXF, HXG, HXI) vs $\mathrm{CaO}$ conversion for a pressure ratio $\mathrm{PR}=3.2$. b) Efficiency vs $\mathrm{CaO}$ conversion (using $\mathrm{PR}=3.2$ ) for selected absolute pressures of the carbonator and turbine outlet, respectively, as indicated. 
The efficiency curve is represented in Figure $6 \mathrm{~b}$ as a function of $\mathrm{CaO}$ conversion $X$ for a fixed pressure ratio $P R=3.2$ used as an optimum value. Efficiencies are shown for the cases of a carbonator operating under atmospheric pressure (expansion to sub atmospheric pressure) and a pressurized carbonator (atmospheric turbine output). As may be seen, efficiency increases with $\mathrm{CaO}$ conversion and reaches a maximum between $44 \%$ and $46 \%$ under the conditions considered. Importantly, the energy consumption related to solids conveying diminishes the efficiency especially in the case of low values of $\mathrm{CaO}$ conversion.

\subsection{Pressure}

The carbonator pressure determines the upper pressure of the Brayton cycle and therefore plays a crucial role in the plant performance. The pressure ratio in the power turbine (T1) influences carbonator side's parameters, mainly temperatures (first of all turbine outlet temperature), flow rates, exchangers' nominal power (and size) and operational parameters. Some system variables show a direct dependence on the pressure ratio $P R$ while others depend separately on the absolute values of the carbonator pressure and turbine outlet pressure.

High pressure ratios yield a reduced temperature at the turbine outlet as seen in Figure 7 where the effect on the temperature of the sorbent $(\mathrm{CaO})$ at the carbonator inlet can be observed too. Note that the optimized heat exchangers configuration adopted in the model yields high and stable values of the $\mathrm{CO}_{2}$ temperature at the carbonator inlet regardless of the pressure ratio. 
Figure 7: Variation of temperatures in the regions encircled in the diagram (according to the colors code) with pressure ratio.

The trends of $\mathrm{CaO}$ and $\mathrm{CO}_{2}$ temperatures at the carbonator inlet, both approaching the carbonator temperature in the limit $P R \rightarrow 1$, yield an infinite $\mathrm{CO}_{2}$ flow rate for removal of the carbonation heat. At higher pressure ratios, $\mathrm{CO}_{2}$ inlet temperature is quite stable while $\mathrm{CaO}$ temperature decreases, absorbing more heat in the reactor and causing the $\mathrm{CO}_{2}$ flow rate to drop as it is seen in Fig. 9b (green curve). For this reason, high pressure ratios are desirable in order to reduce costs related to the limited inventory storage capacity and to the plant machinery size.

\section{Figure 8: Minimum value of $\mathrm{CaO}$ conversion for carbonator isothermal operation vs pressure ratio.}

On the other hand, reduced values of $P R$ allow for less strict operational limits regarding the critical value for $\mathrm{CaO}$ conversion below which no isothermal carbonator operation is possible. Figure 8 shows the minimum $\mathrm{CaO}$ conversion required $X_{\text {lim }}$ in the proposed power cycle as a function of the pressure ratio $P R$. The trend is again justified by the lower $\mathrm{CaO}$ temperatures at the carbonator inlet for increasing values of $P R$.

A detailed scheme of the $\mathrm{CO}_{2}$ reaction turbine $\mathrm{T} 2-\mathrm{CO}_{2}$ cycle compression $\mathrm{C} 1$ group is shown in Figure 9a. The specific work of compression increases with the pressure ratio as seen in Figure 9b. At a fixed pressure ratio, lower absolute pressures are associated with higher specific compression work, thus giving rise to an undesirable increase of compression power. This effect is shown in the blue curve of Fig. 10a where the power (calculated as the product of the $\mathrm{CO}_{2}$ flow rate, following the trend shown in the green curve of Figure $9 \mathrm{~b}$, by the specific work of compression, blue curve) is plotted vs pressure ratio for different values of turbine outlet pressure (shaded scale). 
Figure 9: a) $\mathrm{CO}_{2}$ reaction turbine $-\mathrm{CO}_{2}$ cycle compression group. b) Left axis: Specific work of compression vs pressure ratio $P R$ for several turbine outlet pressures (TOP). TOP=0.1 bar (dashed line) and 1.3 bar (solid line). Right axis: $\mathrm{CO}_{2}$ mass flow rate vs PR.

Figure 10: a) Power balance in the T2/C1 group. Net power consumption (carbonator side) vs pressure ratio for different values of turbine outlet pressure (shaded scale, where arrows direction represents higher TOP values). Solid curves refer to atmospheric turbine output pressure. b) Power balance in the carbonator side. Net power consumption, power generation in the turbine and net power production vs pressure ratio for different values of turbine outlet pressure are shown. A constant value of $\mathrm{CaO}$ conversion $\mathrm{X}=0.5$ is used.

As may be seen in Figure 10a, lower carbonator absolute pressures (and TOP) imply a higher expansion ratio in the turbine $\mathrm{T} 2$ (from 75 bar to carbonator pressure) and a proportional increase of power generation (see the shaded scaling around the green curve in Figure 10a). Thus, smaller absolute pressures determine higher compression power but also higher expansion power. The latter beneficial effect prevails over the former detrimental one, thus the net power consumption of the group is decreased in practice by low absolute pressure values. As can be seen in Figure 10b, the gross power generation in the turbine depends only weakly on the absolute pressures. Hence, better performances are retrieved for lower absolute pressures at a fixed pressure ratio. This explains the global plant efficiency trend with pressures, which is shown in detail in Figure 11 and Figure 12 (note that the energy consumption in compressor $C 2$ does not depend on $P R$ ). Figure 11 demonstrates that, as usually occurs for regenerative Brayton power cycles, there is a maximum in the efficiency-PR curve, occurring in the present case at 3.2 bar. A more detailed representation of the global efficiency achievable, as depending on the carbonator pressure $P$ and turbine outlet pressure $T O P$, is given in the contour plot of Figure 12 where a constant value of $\mathrm{CaO}$ conversion $\mathrm{X}=0.5$ has been assumed.

Figure 11: Plant efficiency as a function of carbonator to turbine outlet pressures ratio (for a fixed $\mathrm{CaO}$ conversion $\mathrm{X}=0.5$ ) and turbine outlet pressure TOP (shaded scaling). The solid line corresponds to TOP $=1$ bar. 
Figure 12: Contour plot of efficiency (assuming a constant value of $\mathrm{CaO}$ conversion $\mathrm{X}=0.5$ ) as depending on carbonator and turbine outlet pressure. Black lines indicate a constant value of pressure ratio.

The effect of gas pressure drops in the $\mathrm{CO}_{2}$ power cycle has been also investigated since viscous frictional forces can be enhanced by the use of a fluidized bed reactors and open cyclone exchangers. Due to pressure drops, the power consumption of the plant increases and the efficiency decreases. At the same time, the maximum of efficiency is shifted to higher pressure ratios albeit the location of the maximum becomes less marked as the pressure drop is increased (see Figure 13). The weighted dotted line joins all the maximums for different values of pressure drops in the power cycle (expressed as percentage of the absolute carbonation pressure).

Figure 13: Influence of pressure drops of $\mathrm{CO}_{2}$ in the circuit on efficiency as a function of pressure ratio PR. Maximum efficiency is decreased and the optimum pressure ratio is increased. Turbine outlet pressure $=1 \mathrm{bar}, \mathrm{CaO}$ conversion $\mathrm{X}=0.5$.

\subsection{Temperature}

In a Brayton cycle, the increase of turbine inlet temperature (which is, in the present case, the carbonator temperature $T$ ) naturally enhances the efficiency. It is therefore crucial to envisage which limits are imposed to the maximum carbonator temperature. A main limitation is linked to the equilibrium of the calcination/carbonation reaction. At a given temperature the reaction reaches equilibrium for a $\mathrm{CO}_{2}$ pressure below which carbonation cannot take place. Equivalently, at a given $\mathrm{CO}_{2}$ pressure, there is a maximum temperature above which carbonation cannot occur. For example, under a pure $\mathrm{CO}_{2}$ environment at atmospheric pressure, equilibrium is reached at $\sim 895 \circ$ C. Carbonation slows down as practical operation 
conditions approach equilibrium [62]. Thus, the closer to equilibrium conditions the smaller will be the quantity of $\mathrm{CO}_{2}$ reacting in the carbonator in practice (Figure 14a).

The equilibrium fraction of $\mathrm{CO}_{2}$ in the carbonator (molar fraction of $\mathrm{CO}_{2}$ at maximum capture efficiency) is defined as [63]:

$$
y_{e q}=\frac{P_{e q}}{P}=\frac{1}{P}\left[4.13710^{12} \exp \left(-\frac{20474}{T}\right)\right]
$$

where $P_{e q}(\mathrm{bar})$ is the $\mathrm{CO}_{2}$ pressure at equilibrium. According to Eq. (8), at a fixed carbonator pressure $P$, an increase of the carbonator temperature yields an increase of the equilibrium pressure of $\mathrm{CO}_{2}$, and thus of $y_{e q}$.

At low temperatures, the $\mathrm{CO}_{2}$ equilibrium pressure is small, thus the equilibrium molar fraction $\left(y_{e q}\right)$ achievable is also very close to 0 and (almost) the entire stoichiometric amount of $\mathrm{CO}_{2}$ can react even though the reaction kinetics will be hindered at very low temperatures [64]. On the other hand, if the temperature is increased, the equilibrium molar fraction of $\mathrm{CO}_{2}$ achievable at the output approaches the $\mathrm{CO}_{2}$ molar fraction at the input since the $\mathrm{CO}_{2}$ pressure in the inlet gas stream becomes closer to the equilibrium pressure $\left(P_{\mathrm{CO}_{2}, \mathrm{carb}, \text { in }} \rightarrow P_{e q}\right)$. When the combination of temperature and $\mathrm{CO}_{2}$ pressure yields an equilibrium molar fraction of $\mathrm{CO}_{2}$ equal to the inlet molar fraction $\left(y_{\mathrm{CO}_{2}, \mathrm{Carb}, \mathrm{in}}\right)$ carbonation is not possible anymore. In the present application, the value of $y_{\mathrm{CO}_{2}, \mathrm{carb}, \text { in }}$ has been maximized by working with pure $\mathrm{CO}_{2}$ in the carbonator, with the consequent relevant improvements in reaction kinetics and reactor efficiency. The equilibrium $\mathrm{CO}_{2}$ reaction efficiency $E_{e q}$, defined as:

$$
E_{e q}=\frac{F_{C O 2, i n}-F_{C O 2, e q}}{F_{C O 2, \text { in }}}
$$

represents the ratio of the $\mathrm{CO}_{2}$ flow rate that reacts in the carbonator to the total $\mathrm{CO}_{2}$ flow rate entering into it as limited by the reaction equilibrium. By increasing the carbonator temperature, the equilibrium $\mathrm{CO}_{2}$ reaction efficiency is decreased (black curve of Figure 14a). 
Thus, more $\mathrm{CO}_{2}$ must be circulated in the loop in order to maintain the desired rate of thermal energy generation in the carbonator (Figure 14b). It is therefore important not to work too close to the equilibrium limit in order to keep $\mathrm{CO}_{2}$ flow rates at a feasible value. Moreover, the reaction kinetics would be slowed down as equilibrium is approached [64]. Note that the above means that higher carbonator pressures may yield an increase of efficiency through a carbonation temperature upgrade, as shown in the dotted curves of Figure 14a.

Figure 14: a) Left axis: Carbonator capture efficiency vs temperature in the case of fully achieved carbonation (blue curve) and equilibrium capture efficiency (black curve) for carbonator pressures of 3.2 (solid line) and 8 (dotted line) bar (fixed pressure ratio PR= 3.2). Right axis: equilibrium and inlet molar fraction of $\mathrm{CO}_{2}$ vs temperature. b) $\mathrm{CO}_{2}$ molar flow rate through the carbonator vs carbonation temperature. Note that pure $\mathrm{CO}_{2}$ is used in the carbonator as working fluid ( $\mathrm{y}_{\mathrm{co2}}$, carb, in $=1$ as represented by the top red line).

\subsection{Combined effect of temperature, pressure ratio and carbonator pressure}

The search for an optimum operation point that might result from a specific combination of temperature, carbonator pressure and pressure ratio is not straightforward. On one side, despite low absolute pressures are beneficial for increasing the efficiency at a fixed carbonator temperature, high pressures allow for further temperature upgrading, which yields higher efficiency. This is shown in Figure 15 where the red curve, corresponding to low absolute pressures (turbine outlet pressure of 1 bar) shows a maximum efficiency of $42.6 \%$ at $875^{\circ} \mathrm{C}$ for $P R=3.2$. If absolute pressures are increased, operation at the optimum pressure ratio may be possible at an increased temperature of $950^{\circ} \mathrm{C}$, thus increasing the efficiency through a temperature upgrade despite the higher absolute pressure.

Note that in Error! Reference source not found. the $\mathrm{CO}_{2}$ flow rate is calculated by taking into account the real equilibrium limitations (as shown in Figure 14b). The dashed part of the curves in Error! Reference source not found. represent a constrained operation range on the circulating rates set by an equilibrium molar fraction of $\mathrm{CO}_{2}$ in the carbonator exceeding 0.3. 
Figure 15: Efficiency as a function of PR for different values of carbonation temperature and turbine outlet pressure. Red curve: turbine outlet pressure $=1$ bar, carbonation temperature $=$ $875^{\circ} \mathrm{C}$; operation point (max efficiency): carbonator pressure=3.2 bar ( $P R=3.2$ ). Purple curve: turbine outlet pressure $=4$ bar, carbonation temperature $=950^{\circ} \mathrm{C}$; operation point: carbonator pressure=14.8 bar ( $P R=3.7)$. The dashed part of the curves corresponds to $\mathrm{CO}_{2}$ equilibrium molar fraction>0.3. It can be seen that working at the optimum point with higher absolute pressures enhances efficiency through a temperature upgrade.

Despite the maximum in the efficiency curve occurs at pressure ratios around 3, the molar flow rates (and the size of all exchangers, in particular the exchanger $\mathrm{HXG}$ ) can be considerably reduced through an increase of the pressure ratio without efficiency penalizations. If the carbonator pressure is increased higher carbonation temperatures are in fact achievable and therefore the same efficiency can be reached through optimizing costs as shown in Figure 16.

Figure 16: Efficiency as a function of PR for different values of the carbonation temperature. Red curve: turbine outlet pressure $=1$ bar, carbonation temperature $=875^{\circ} \mathrm{C}$; operation point: carbonator pressure=3.2 bar ( $P R=3.2$ ). Blue curve: turbine outlet pressure=1 bar, carbonation temperature $=950^{\circ} \mathrm{C}$; operation point: carbonator pressure $=9.2 \mathrm{bar}(\mathrm{PR}=9.2)$. The dashed part of the curves corresponds to $\mathrm{CO}_{2}$ equilibrium molar fraction>0.3. The horizontal arrow shows that working at higher pressure ratios is possible without penalizing efficiency through a temperature upgrade.

Summarizing, the analysis carried out yields the following main conclusions:

- Thermal optimization of the power cycle increase the global plant efficiency and invert the negative trend of the efficiency with increasing $\mathrm{CaO}$ average conversion in the carbonator $(X)$ that was inferred from a previous work [18]. The optimum configuration with exchangers HXE, HXF, HXG and HXI yield high integration efficiencies.

- Achieving high values of $\mathrm{CaO}$ conversion $X$ is beneficial for every aspect: higher efficiency, amount of passive solids reduction, lower size of silos and storage, lower size of exchangers and lower fresh sorbent makeup flow (in the case it was needed). Nevertheless, the nominal power of the regenerator HXG increases with $X$ and this can lead to a disproportionate increase of cost unless pressure ratio is increased. 
- The optimal pressure ratio value is found at low values ( $P R$ around 3.2) although several issues must be remarked:

- Pressure ratios below the maximum must be avoided because they lead to a notable efficiency drop.

- Pressure ratios above the maximum only generate a slow decrease in efficiency.

- The presence of frictional pressure losses in the $\mathrm{CO}_{2}$ circuit decreases the maximum efficiency and shifts the maximum to higher $P R$ (around $P R=4.8$ when pressure losses are $20 \%$ of the carbonator pressure $P, P R=7.1$ when they are $50 \% P$ ). Besides, it stabilizes the efficiency value for a wide range of pressure ratios (e.g. if $20 \% P$ pressure losses occur, the optimum point is at $P R=5$ but the efficiency variation is below $1 \%$ for PR in the range $2.8-10$ ).

- The $\mathrm{CO}_{2}$ flow rate needed in the power cycle reaches very high values when pressure ratios are small (At $X=0.5$ it should be $>300 \mathrm{~kg} / \mathrm{s}$ for $\mathrm{PR}<2 ;>200 \mathrm{~kg} / \mathrm{s}$ for $\mathrm{PR}<2.8 ;<100$ $\mathrm{kg} / \mathrm{s}$ for $\mathrm{PR}>10)$.

- Consequently, the nominal power (thus size and cost) of all heat exchangers can be reduced by increasing the pressure ratio. This concerns in particular the regenerator HXG (the most affected one by the $\mathrm{CO}_{2}$ flow rate) whose size is reduced by 3 to 4 times when $P R$ is increased from $P R=3$ to $P R=9$.

- Despite the (although small) efficiency drop, high pressure ratios are therefore desirable to reduce the circulating $\mathrm{CO}_{2}$ flow rate and the size of exchanger $\mathrm{HXG}$, in particular if the $\mathrm{CaO}$ solids show a high value of conversion $X$. The unavoidable presence of gas pressure losses makes this choice less penalizing from the efficiency point of view.

- The role of absolute carbonator and turbine outlet pressure on the plant efficiency is significant: 
- Lower absolute pressures yield higher performances at fixed carbonator temperature thanks to the higher $\mathrm{CO}_{2}$ turbine $\mathrm{T} 2$ expansion ratio.

- Nevertheless, high carbonator pressures ensure from equilibrium considerations higher temperature achievable in the carbonation reaction with the consequent efficiency upgrade.

- At same time, at low pressures the specific volume of $\mathrm{CO}_{2}$ may lead to an excessive increase of the size of the gas turbine and pipelines (especially for turbine outlet below atmospheric pressure).

\subsection{Limestone derived $\mathrm{CaO}$ conversion at CSP-CaL integration conditions}

The combined effects of pressure ratio, carbonator pressure and temperature must be carefully re-evaluated once the value of residual $\mathrm{CaO}$ conversion achievable under the specific CaL operating conditions for the CSP-CaL integration is determined from lab-scale experimental measurements. It is important to remind here that most of previous lab-scale experimental measurements on the multicycle conversion of limestone derived $\mathrm{CaO}$ are carried out at the standard conditions corresponding to the CaL process for $\mathrm{CO}_{2}$ capture [28]. These are rather different from those to be found in the CSP-CaL integration at the optimum efficiency operating conditions inferred from the present work.

The CaL process requires usually a periodic purge of deactivated sorbent, which must be compensated by a makeup flow of fresh limestone in order to keep de mass balance. This is indeed the case of the $\mathrm{CaL}$ process for $\mathrm{CO}_{2}$ capture. The specific $\mathrm{CaL}$ conditions for this integration involve calcination under high temperature at high $\mathrm{CO}_{2}$ partial pressure and 
carbonation under low $\mathrm{CO}_{2}$ partial pressure, which give rise to a severe drop of the $\mathrm{CaO}$ conversion after only a few cycles. After a large number of cycles $\mathrm{CaO}$ conversion converges asymptotically towards a residual value of just about $0.07[65,66]$. However, the specific conditions for an efficient integration of the CaL process into CSP plants involve, as seen above, carbonation under high $\mathrm{CO}_{2}$ partial pressure at high temperatures. Figure 17 shows recently obtained experimental results on the conversion of limestone derived $\mathrm{CaO}$ as a function of the calcination/carbonation cycle number $\mathrm{N}$ under $\mathrm{CaL}$ conditions specific for both $\mathrm{CO}_{2}$ capture and CSP energy storage [44].

Figure 17: Multicycle conversion of limestone derived $\mathrm{CaO}$ as obtained from thermogravimetric analysis (TGA) tests under different CaL conditions (reported in [44]). CSP storage conditions: carbonation at $850 \circ \mathrm{C}$ under pure $\mathrm{CO}_{2}$ and calcination at 700 - $\mathrm{C}$ under pure $\mathrm{He}$. $\mathrm{CO}_{2}$ capture conditions: Carbonation at 650 - $\mathrm{C}$ under a $15 \% \mathrm{CO}_{2} / 85 \%$ air vol/vol atmosphere and calcination at 950 - C under a $70 \% \mathrm{CO}_{2} / 30 \%$ air vol/vol atmosphere. Residence times at both stages were 5 $\mathrm{min}$. The solid lines are best fits from Eq. 10 to data.

The experimental results shown in Figure 17 highlight the radical different behavior of natural limestone derived $\mathrm{CaO}$ as depending on the $\mathrm{CaL}$ conditions. In order to find out a value of the residual $\mathrm{CaO}$ conversion $\mathrm{Xr}$, the semi-empirical equation (10) can be fitted to conversion data [66].

$$
\frac{X_{N}}{X_{1}}=\frac{X_{r}}{X_{1}}+\left(\frac{1}{\kappa(N-1)+\left(1-\frac{X_{r}}{X_{1}}\right)^{-1}}\right)
$$

Thus, the obtained residual $\mathrm{CaO}$ conversion is just about 0.08 for $\mathrm{CO}_{2}$ capture conditions whereas it becomes as large as $X_{r}=0.53$ for conditions that correspond to the CSP-CaL integration. Expectedly, this value will be even higher when the $\mathrm{CaO}$ solids are carbonated under $\mathrm{CO}_{2}$ at over atmospheric pressure, which will enhance the reaction kinetics and increase the equilibrium temperature, thus allowing carbonation at even higher temperatures [62]. Importantly, this high residual $\mathrm{CaO}$ conversion is obtained for residence times of just 5 minutes 
both in the carbonation and calcination stages [44]. This would allow in practice the use of circulating fluidized bed (CFB) reactors that ensure a highly efficient transfer of mass and heat for solid-gas reactions and whose suitability to the $\mathrm{CaL}$ process is already proven in $\mathrm{CO}_{2}$ capture pilot plants. Note that fast calcination is achieved at a reduced temperature of just 700 ㅇ $\mathrm{C}$ under a gas which is easily separated from $\mathrm{CO}_{2}$ (either He as in the TGA experiments or superheated steam as in Catalytic Flash Calcination technology [52]), which would allow also for the use of already mature and inexpensive metallic solar receivers thus reducing technological risks.

\section{Sensitivity analysis}

The results from a sensitivity analysis of the intervening parameters on plant efficiency are shown in Figure 18 and Figure 19 using the data reported in Table 3. In Figure 18 a sensitivity analysis on the effects of ambient temperature, heat exchangers design and solar daylight hours is presented whereas in Figure 19 the effects on global plant efficiency of carbonator thermal dispersion, transport losses and storage pressure are shown. Reference values are obtained for $X=0.5$, carbonator pressure of 3.2 bar, turbine outlet pressure of 1 bar and carbonator temperature of $875^{\circ} \mathrm{C}$.

Table 3: Sensitivity Analysis Data

Figure 18: Efficiency variation derived from a sensitivity analysis on ambient temperature, heat exchangers and solar daylight hours using as reference values those shown in Table 3.

Figure 19: Efficiency variation derived from a sensitivity analysis on carbonator thermal dispersion, system transport and storage pressure using as reference values those shown in Table 3.

According to the results obtained from the sensitivity analysis carried out on diverse parameters (Figure 18 and Figure 19) the following main conclusions may be drawn: 
- The sensitivity of efficiency to ambient temperature is high. An ambient temperature variation of $20^{\circ} \mathrm{C}$ leads to a $6 \%$ relative variation of efficiency. The same increase leads to roughly $250 \%$ bigger volumes when storage pressure is 75 bar. By increasing the storage pressure above 100 bar, the volume growth is more restricted (around 36\%). Due to the high ambient temperatures typically present in CSP plant emplacements, the addition of gas-cooling devices upstream compression to avoid this effect should be considered.

- A $\pm 70 \%$ variation of exchangers' approach temperatures (excluded the gas-gas regenerator) produces a modest efficiency variation, which is below $3 \%$ in relative terms.

- Unlike for the other heat exchangers, the approach temperature of the regenerator HXG (gas-gas exchanger) has a critical effect on performance. Reducing the value of $\Delta T_{\min }$ by $10^{\circ} \mathrm{C}$ leads to a relative increase of efficiency greater than $7 \%$, passing from $42.6 \%$ to $45.6 \%$ in absolute value.

- Thermal dispersions in the carbonator and pipework have a major influence on efficiency: a decrease of thermal dispersion from $10 \%$ down to $2 \%$ of the reaction heat can lead to over $10 \%$ relative higher efficiency. This issue highlights the importance of providing efficient insulation to the hot components.

- A 150 m conveying distance variation produces a relative efficiency variation below $3 \%$. The same variation is caused by an $8 \mathrm{MJ} / 100 \mathrm{~m} /$ ton change of the specific conveying consumption factor.

- Solids conveying energy consumption, as noted in previous paragraphs, can be quite critical if high values of $\mathrm{CaO}$ conversion are not achievable due to the higher amounts of solids in the loop.

- The impact of pressure drops in the gas circuit is very relevant, with a $12 \%$ relative efficiency decrease when going from $0 \%$ pressure losses to $20 \%$ losses (\% referred to the carbonator pressure). 
- The number of solar daylight hours influences the amounts of dissociated products ( $\mathrm{CaO}$ and $\mathrm{CO}_{2}$ ) available at the beginning of the day for energy production in the discharge phase.

\section{Conclusions}

This paper explores a thermochemical energy storage concept in Concentrated Solar Power plants (CSP) based on the Calcium Looping process (CaL), which allows a fully decoupled operation of charge and discharge phases for long periods. It uses an abundant, geographically widespread, cheap and non-toxic raw material such as limestone. Moreover, the multicycle conversion of limestone derived $\mathrm{CaO}$ at specific $\mathrm{CaL}$ conditions for integration in CSP plants converges towards a rather high residual value as recently demonstrated by lab-scale TGA results. Therefore, affordable costs can be expected.

The proposed CSP-CaL integration is technically feasible with mature technologies already available in the market for input heat powers (net heat supply at the calciner) ranging from small to above $100 \mathrm{MW}_{\text {th }}$ values. It uses a pressurized fluidized reactor for carbonation, solids pneumatic conveying technology, gas-solid cyclone/closed heat exchangers, gas-gas regenerators, a pressurized storage vessel at 75 bar for $\mathrm{CO}_{2}$, two atmospheric silos for $\mathrm{CaO}$ and $\mathrm{CaCO}_{3}$ storage, and conventional intercooling compressor and turbine systems. A main feature of the integration is that a closed $\mathrm{CO}_{2}$ circuit is used for operation of both the CaL process and the power cycle.

The analyses presented in the paper shows that for a ratio of carbonator to outlet turbine pressures of 3.2 bars, and a carbonator temperature of $875 \stackrel{\circ}{ } \mathrm{C}$, plant efficiencies above $45 \%$ may be reached. The optimized CSP-CaL integration provides several benefits over previous studies, including complete absence of $\mathrm{CO}_{2}$ released from the system, improved kinetics in the carbonator at elevated temperatures and high $\mathrm{CO}_{2}$ pressures, high carbonator temperatures 
attainable and high thermal efficiency values. First law efficiency of $40-46 \%$ and second law efficiency of $43 \%-48 \%$ are achievable under realistic conditions and taking into account heat losses, pressure drops and conveying energy consumption. According to our study, the main parameters to improve the proposed cycle are similar to those used in other power cycles, namely, turbine inlet temperature, pressure ratio in the Brayton turbine, boiler/reactor/heat exchangers' efficiency or pressure losses taking into account the particularities linked to chemical equilibrium and reaction kinetics as determined by $\mathrm{CO}_{2}$ partial pressure and temperature.

The competitiveness of the proposed integration is reinforced by the fact that the obtained efficiency is higher than that of Rankine cycles traditionally employed in CSP plants. A detailed economic assessment is out of the scope of the present manuscript. However, it is estimated elsewhere that an efficient CSP-CaL integration would reduce the cost of Levelized Cost of Electricity (LCOE) below 7c€/kWh (see SUNSHOT program [67]). This estimation takes into account further improvements in the solar field, receiver and power block and considers a thermochemical energy storage cost below $\$ 15 / \mathrm{kWh}_{\mathrm{th}}$.

\section{Acknowledgements}

This work was supported by the Andalusian Regional Government Junta de Andalucia (contract FQM-5735) and Spanish Government Agency Ministerio de Economia y Competitividad and FEDER Funds (contracts CTQ2014-52763-C2-1-R, CTQ2014-52763-C2-2-R and MAT2013-41233$\mathrm{R})$.

\section{Notation}

\begin{tabular}{|c|c|c|c|}
\hline $\mathrm{C} 1$ & $\begin{array}{l}\mathrm{CO}_{2} \text { compressor (from } \mathrm{T} 1 \text { outlet to } \\
\text { carbonator pressure) }\end{array}$ & HXG & gas-solid heat exchanger \\
\hline $\mathrm{C} 2$ & $\begin{array}{c}\mathrm{CO}_{2} \text { compressor (from calciner to } \\
\text { storage pressure) }\end{array}$ & $\dot{m}_{C O 2, c r b}$ & $\mathrm{CO}_{2}$ mass flow rate through carbonator \\
\hline$c_{p, i}$ & Specific heat, $\mathrm{kJ} /(\mathrm{kmol} \cdot \mathrm{K})$ & $P$ & absolute carbonator pressure, bar \\
\hline$E_{e q}$ & equilibrium $\mathrm{CO}_{2}$ reaction efficiency & $P_{e q}$ & $\mathrm{CO}_{2}$ partial pressure at equilibrium, bar \\
\hline$F_{i}$ & $\begin{array}{l}\text { molar flow rate of component } \mathrm{i} \text {, } \\
\mathrm{kmol} / \mathrm{s}\end{array}$ & $P R$ & pressure ratio (between $P$ and $T O P$ ) \\
\hline $\mathrm{F}_{\mathrm{CaCO}_{3}}$ & molar flow rate of $\mathrm{CaCO}_{3}$ & $p_{\text {drop }}$ & pressure drops in $\mathrm{CO}_{2}$ circuit, bar \\
\hline$F_{\mathrm{CaCO}, \mathrm{carb}}$ & $\begin{array}{l}\text { molar flow rate of } \mathrm{CaCO}_{3} \text { (carbonator } \\
\text { side) }\end{array}$ & $y_{C O 2, c a r b, i n}$ & $\begin{array}{l}\text { inlet molar fraction of } \mathrm{CO}_{2} \text { in the } \\
\text { carbonator }\end{array}$ \\
\hline
\end{tabular}




\begin{tabular}{|c|c|c|c|}
\hline$F_{\mathrm{CaCO}, \mathrm{clc}}$ & $\begin{array}{l}\text { molar flow rate of } \mathrm{CaCO}_{3} \text { (calciner } \\
\text { side) }\end{array}$ & $y_{e q}$ & $\begin{array}{l}\text { equilibrium fraction of } \mathrm{CO}_{2} \text { in the } \\
\text { carbonator }\end{array}$ \\
\hline$F_{C a O, c r b}$ & $\begin{array}{c}\text { molar flow rate of } \mathrm{CaO} \text { (carbonator } \\
\text { side) }\end{array}$ & $T$ & Temperature, $\mathrm{K}$ \\
\hline$F_{\mathrm{CaO}, \mathrm{clc}}$ & $\begin{array}{c}\text { molar flow rate of regenerated } \\
\text { sorbent }\end{array}$ & TOP & T1 outlet pressure, bar \\
\hline$F_{\text {CaO,unr,carb }}$ & $\begin{array}{l}\text { molar flow rate of unreacted } \mathrm{CaO} \\
\text { (carbonator side) }\end{array}$ & $\mathrm{T} 1$ & $\mathrm{CO}_{2}$ turbine (at carbonator outlet ) \\
\hline$F_{\text {CaO,unr,clc }}$ & $\begin{array}{l}\text { molar flow rate of unreacted } \mathrm{CaO} \\
\text { (calciner side) }\end{array}$ & $\mathrm{T} 2$ & $\begin{array}{c}\mathrm{CO}_{2} \text { turbine (from storage to carbonator } \\
\text { pressure) }\end{array}$ \\
\hline $\mathrm{F}_{\mathrm{CO}_{2}, \text { clc }, \text { out }}$ & $\begin{array}{l}\text { molar flow rate of } \mathrm{CO}_{2} \text { at calciner } \\
\text { outlet }\end{array}$ & $\dot{W}$ & mechanical power, $\mathrm{kW}$ \\
\hline$F_{\mathrm{CO}_{2}, \mathrm{~S}}$ & $\begin{array}{l}\mathrm{CO}_{2} \text { looped fraction flowing in the } \\
\text { carbonator side }\end{array}$ & $X$ & CaO conversion $X$ \\
\hline$F_{R, c a r b}$ & $\begin{array}{l}\text { recirculating molar flow rate } \\
\text { (carbonator side) }\end{array}$ & $X_{\lim }$ & $\begin{array}{c}\text { minimum critical value of } \mathrm{CaO} \\
\text { conversion }\end{array}$ \\
\hline$F_{R, c l c}$ & $\begin{array}{l}\text { recirculating molar flow rate } \\
\text { (calciner side) }\end{array}$ & $X_{N}$ & $\mathrm{CaO}$ conversion in the $\mathrm{N}$ cycle \\
\hline$h_{i}$ & Enthalpy, kJ/kmol & $X_{r}$ & residual $\mathrm{CaO}$ conversion \\
\hline HXA & solid-solid heat exchanger & $\Delta t_{\text {sun }}$ & average daytime period \\
\hline HXB & gas-solid heat exchanger & $\Delta H_{R}\left(T_{\text {react }}\right)$ & $\begin{array}{l}\text { heat of reaction at the reactor } \\
\text { temperature }\end{array}$ \\
\hline HXE & gas-solid heat exchanger & $\xi$ & extent of reaction per unit time \\
\hline HXF & gas-solid heat exchanger & $\Phi$ & heat flux \\
\hline HXI & gas-solid heat exchanger & $\Phi_{\text {carbonation }}$ & available heat of carbonation \\
\hline $\mathrm{k}$ & $\mathrm{CaO}$ deactivation constant & & \\
\hline
\end{tabular}

\section{References}

[1] N'Tsoukpoe KE, Liu H, Le Pierrès N, Luo L. A review on long-term sorption solar energy storage. Renew Sustain Energy Rev 2009;13:2385-96. doi:10.1016/j.rser.2009.05.008.

[2] Mahlia TMI, Saktisahdan TJ, Jannifar a., Hasan MH, Matseelar HSC. A review of available methods and development on energy storage; Technology update. Renew Sustain Energy Rev 2014;33:532-45. doi:10.1016/j.rser.2014.01.068.

[3] Medrano M, Gil A, Martorell I, Potau X, Cabeza LF. State of the art on high-temperature thermal energy storage for power generation. Part 2-Case studies. Renew Sustain Energy Rev 2010;14:56-72. doi:10.1016/j.rser.2009.07.036.

[4] Paksoy HÖ. Thermal Energy Storage for Sustainable Energy Consumption. 2007.

[5] Kearney D, Kelly B, Herrmann U, Cable R, Pacheco J, Mahoney R, et al. Engineering aspects of a molten salt heat transfer fluid in a trough solar field. Energy 2004;29:861- 
70. doi:10.1016/S0360-5442(03)00191-9.

[6] Fernández AG, Ushak S, Galleguillos H, Pérez FJ. Development of new molten salts with LiNO3 and $\mathrm{Ca}(\mathrm{NO3}) 2$ for energy storage in CSP plants. Appl Energy 2014;119:131-40. doi:10.1016/j.apenergy.2013.12.061.

[7] Rodríguez I, Pérez-Segarra CD, Lehmkuhl O, Oliva A. Modular object-oriented methodology for the resolution of molten salt storage tanks for CSP plants. Appl Energy 2013;109:402-14. doi:10.1016/j.apenergy.2012.11.008.

[8] Kuravi S, Goswami DY, Stefanakos EK, Ram M, Jotshi C, Trahan J, et al. THERMAL ENERGY STORAGE FOR CONCENTRATING SOLAR POWER PLANTS Sarada Kuravi, D. Yogi Goswami, Elias K. Stefanakos, Manoj Ram, Chand Jotshi, Swetha Pendyala, Jamie Trahan, Prashanth Sridharan, Muhammad Rahman and Burton Krakow Clean Energy Research Center, U n.d.

[9] Karagiannakis G, Pagkoura C, Zygogianni A, Lorentzou S, Konstandopoulos AG. Monolithic Ceramic Redox Materials for Thermochemical Heat Storage Applications in CSP Plants. Energy Procedia 2014;49:820-9. doi:10.1016/j.egypro.2014.03.089.

[10] Zalba B, Marín JM, Cabeza LF, Mehling H. Review on thermal energy storage with phase change: materials, heat transfer analysis and applications. vol. 23. 2003. doi:10.1016/S1359-4311(02)00192-8.

[11] Tian Y, Zhao CY. A review of solar collectors and thermal energy storage in solar thermal applications. Appl Energy 2013;104:538-53. doi:10.1016/j.apenergy.2012.11.051.

[12] Nithyanandam K, Pitchumani R. Design of a latent thermal energy storage system with embedded heat pipes. Appl Energy 2014;126:266-80. doi:10.1016/j.apenergy.2014.03.025.

[13] Sharma A, Tyagi VV, Chen CR, Buddhi D. Review on thermal energy storage with phase 
change materials and applications. Renew Sustain Energy Rev 2009;13:318-45. doi:10.1016/j.rser.2007.10.005.

[14] Pardo P, Deydier a., Anxionnaz-Minvielle Z, Rougé S, Cabassud M, Cognet P. A review on high temperature thermochemical heat energy storage. Renew Sustain Energy Rev 2014;32:591-610. doi:10.1016/j.rser.2013.12.014.

[15] Li TX, Wu S, Yan T, Xu JX, Wang RZ. A novel solid-gas thermochemical multilevel sorption thermal battery for cascaded solar thermal energy storage. Appl Energy 2016;161:1-10. doi:10.1016/j.apenergy.2015.09.084.

[16] Kyaw K, Matsuda H, Hasatani M. Applicability of Carbonation/Decarbonation Reactions to High-Temperature Thermal Energy Storage and Temperature Upgrading. J Chem Eng JAPAN 1996;29:119-25. doi:10.1252/jcej.29.119.

[17] Abedin A, Rosen M. A Critical Review of Thermochemical Energy Storage Systems. Open Renew Energy J n.d.:42-6. doi:10.2174/1876387101004010042.

[18] Edwards SEB, Materić V. Calcium looping in solar power generation plants. Sol Energy 2012;86:2494-503. doi:10.1016/j.solener.2012.05.019.

[19] Sakellariou KG, Karagiannakis G, Criado YA, Konstandopoulos AG. Calcium oxide based materials for thermochemical heat storage in concentrated solar power plants. Sol Energy 2015;122:215-30. doi:10.1016/j.solener.2015.08.011.

[20] Ortega-Fernández I, Calvet N, Gil A, Rodríguez-Aseguinolaza J, Faik A, D’Aguanno B. Thermophysical characterization of a by-product from the steel industry to be used as a sustainable and low-cost thermal energy storage material. Energy 2015;89:601-9. doi:10.1016/j.energy.2015.05.153.

[21] Peng Q, Yang X, Ding J, Wei X, Yang J. Design of new molten salt thermal energy storage material for solar thermal power plant. Appl Energy 2013;112:682-9. 
doi:10.1016/j.apenergy.2012.10.048.

[22] Peng Q, Ding J, Wei X, Yang J, Yang X. The preparation and properties of multicomponent molten salts. Appl Energy 2010;87:2812-7. doi:10.1016/j.apenergy.2009.06.022.

[23] Vignarooban K, Xu X, Arvay A, Hsu K, Kannan AM. Heat transfer fluids for concentrating solar power systems - A review. Appl Energy 2015;146:383-96. doi:10.1016/j.apenergy.2015.01.125.

[24] Rodriguez N, Alonso M, Grasa G, Abanades JC. Heat requirements in a calciner of $\mathrm{CaCO} 3$ integrated in a CO2 capture system using CaO. Chem Eng J 2008;138:148-54. doi:10.1016/j.cej.2007.06.005.

[25] Martínez A, Lara $Y$, Lisbona $P$, Romeo LM. Energy penalty reduction in the calcium looping cycle. Int J Greenh Gas Control 2012;7:74-81. doi:10.1016/j.ijggc.2011.12.005.

[26] Kim K, Kim D, Park Y, Soon K. International Journal of Greenhouse Gas Control A solid sorbent-based multi-stage fluidized bed process with inter-stage heat integration as an energy efficient carbon capture process. Int J Greenh Gas Control 2014;26:135-46. doi:10.1016/j.ijggc.2014.03.012.

[27] Ylätalo J, Ritvanen J, Tynjälä T, Hyppänen T. Model based scale-up study of the calcium looping process. Fuel 2014;115:329-37. doi:10.1016/j.fuel.2013.07.036.

[28] Perejon A, Romeo LM, Lara Y, Lisbona P, Valverde JM. The Calcium-Looping technology for $\mathrm{CO} 2$ capture: On the important roles of energy integration and sorbent behavior. Appl Energy 2015;162:787-807. doi:10.1016/j.apenergy.2015.10.121.

[29] Romano MC. Modeling the carbonator of a Ca-looping process for $\mathrm{CO} 2$ capture from power plant flue gas. Chem Eng Sci 2012;69:257-69. doi:10.1016/j.ces.2011.10.041.

[30] Ortiz C, Chacartegui R, Valverde J, Becerra J, Perez-Maqueda L. A new model of the 
carbonator reactor in the calcium looping technology for post-combustion CO 2 capture. FUEL 2015;160:328-38. doi:10.1016/j.fuel.2015.07.095.

[31] Charitos a., Hawthorne C, Bidwe a. R, Sivalingam S, Schuster a., Spliethoff $H$, et al. Parametric investigation of the calcium looping process for $\mathrm{CO} 2$ capture in a $10 \mathrm{kWth}$ dual fluidized bed. Int J Greenh Gas Control 2010;4:776-84. doi:10.1016/j.ijggc.2010.04.009.

[32] Hanak DP, Anthony EJ, Manovic V. A review of developments in pilot-plant testing and modelling of calcium looping process for $\mathrm{CO} 2$ capture from power generation systems. Energy Environ Sci 2015. doi:10.1039/C5EE01228G.

[33] Lara Y, Lisbona P, Martínez A, Romeo LM. Design and analysis of heat exchanger networks for integrated Ca-looping systems. Appl Energy 2013;111:690-700. doi:10.1016/j.apenergy.2013.05.044.

[34] Shimizu T, Hirama T, Hosoda H, Kitano K, Inagaki M, Tejima K. A Twin Fluid-Bed Reactor for Removal of CO2 from Combustion Processes. Chem Eng Res Des 1999;77:62-8. doi:10.1205/026387699525882.

[35] Yang Y, Zhai R, Duan L, Kavosh M, Patchigolla K, Oakey J. Integration and evaluation of a power plant with a CaO-based $\mathrm{CO} 2$ capture system. Int J Greenh Gas Control 2010;4:603-12. doi:10.1016/j.ijggc.2010.01.004.

[36] Lasheras A, Ströhle J, Galloy A, Epple B. Carbonate looping process simulation using a 1D fluidized bed model for the carbonator. Int J Greenh Gas Control 2011;5:686-93. doi:10.1016/j.ijggc.2011.01.005.

[37] Arias B, Diego ME, Abanades JC, Lorenzo M, Diaz L, Martínez D, et al. Demonstration of steady state $\mathrm{CO} 2$ capture in a $1.7 \mathrm{MWth}$ calcium looping pilot. Int J Greenh Gas Control 2013;18:237-45. doi:10.1016/j.jjggc.2013.07.014. 
[38] Ströhle J, Junk M, Kremer J, Galloy A, Epple B. Carbonate looping experiments in a 1 MWth pilot plant and model validation. Fuel 2014;127:13-22. doi:10.1016/j.fuel.2013.12.043.

[39] Ortiz C, Chacartegui R, Valverde JM, Becerra JA. A new integration model of the calcium looping technology into coal fired power plants for CO2 capture. Appl Energy 2016;169:408-20. doi:10.1016/j.apenergy.2016.02.050.

[40] Tregambi C, Montagnaro F, Salatino P, Solimene R. A model of integrated calcium looping for CO2 capture and concentrated solar power. Sol Energy 2015;120:208-20. doi:10.1016/j.solener.2015.07.017.

[41] Abanades JC. The maximum capture efficiency of $\mathrm{CO} 2$ using a carbonation/calcination cycle of $\mathrm{CaO} / \mathrm{CaCO}$. Chem Eng J 2002;90:303-6. doi:10.1016/S1385-8947(02)00126-2.

[42] Abanades JC, Alvarez D. Conversion limits in the reaction of CO2 with lime. Energy and Fuels 2003;17:308-15. doi:10.1021/ef020152a.

[43] Rhodes NR, Barde A, Randhir K, Li L, Hahn DW, Mei R, et al. Solar Thermochemical Energy Storage Through Carbonation Cycles of $\mathrm{SrCO}_{3} / \mathrm{SrO}$ Supported on $\mathrm{SrZrO}_{3}$. ChemSusChem 2015:n/a - n/a. doi:10.1002/cssc.201501023.

[44] Sarrion B, Valverde JM, Perejon A, Perez-maqueda LA, Sanchez-jimenez PE. Cheap , efficient and non-toxic Thermochemical Energy Storage of Concentrated Solar Power (to be published in Energy Technology) 2016.

[45] Meier A, Bonaldi E, Cella GM, Lipinski W, Wuillemin D. Solar chemical reactor technology for industrial production of lime. Sol Energy 2006;80:1355-62. doi:10.1016/j.solener.2005.05.017.

[46] Badie JM, Bonet C, Faure M, Flamant G, Foro R, Hernandez D. 52 Decarbonation of calcite and phosphate rock in solar chemical reactors. Chem Eng Sci 1980;35:413-20. 
doi:10.1016/0009-2509(80)80114-X.

[47] Meier A, Bonaldi E, Cella GM, Lipinski W, Wuillemin D, Palumbo R. Design and experimental investigation of a horizontal rotary reactor for the solar thermal production of lime. Energy 2004;29:811-21. doi:10.1016/S0360-5442(03)00187-7.

[48] Meier A, Bonaldi E, Cella GM, Lipinski W. Multitube Rotary Kiln for the Industrial Solar Production of Lime. J Sol Energy Eng 2005;127:386. doi:10.1115/1.1979517.

[49] Imhof a. Decomposition of limestone in a solar reactor. Renew Energy 1996;9:661-3. doi:10.1016/0960-1481(96)88373-X.

[50] Winter CJ, Sizmann RL, Vant-Hull LL. Solar power plants: fundamentals, technology, systems, economics. Springer-Verlag; 1991.

[51] Valverde JM, Sanchez-Jimenez PE, Perez-Maqueda L. Limestone Calcination Nearby Equilibrium: Kinetics, CaO Crystal Structure, Sintering and Reactivity. J Phys Chem C 2015;119:1623-41. doi:10.1021/jp508745u.

[52] Sceats G, Horley CJ, Richardson P, Sceats MG. System and method for the calcination of minerals. WO2007112496A1, 2014.

[53] Berger EE. Effect of Steam on the Decomposition of Limestone. Ind Eng Chem 1927;19:594-6. doi:10.1021/ie50209a026.

[54] Wang Y, Lin S, Suzuki Y. CO2/Steam and CO2/N2 Atmospheres. Energy 2008:2326-31.

[55] Ávila-Marín AL. Volumetric receivers in Solar Thermal Power Plants with Central Receiver System technology: A review. Sol Energy 2011;85:891-910. doi:10.1016/j.solener.2011.02.002.

[56] Yu FC, Fan LS. Kinetic Study of High-Pressure Carbonation Reaction of Calcium-Based Sorbents in the Calcium Looping Process (CLP). Ind Eng Chem Res 2011;50:11528-36. 
doi:Doi 10.1021/le200914e.

[57] Mills D. Pneumatic conveying design guide 2004:80.

[58] Shimizu A, Yokomine T, Nagafuchi T. Development of gas-solid direct contact heat exchanger by use of axial flow cyclone. Int J Heat Mass Transf 2004;47:4601-14. doi:10.1016/j.ijheatmasstransfer.2003.10.045

[59] Jordison N, Rozendaal NA, Huang PXD. Indirect-heat thermal processing of particulate material, 2007.

[60] Marechal F. PROCESS INTEGRATION AND IMPROVEMENT. EXERGY, ENERGY Syst. Anal. Optim., vol. I, n.d.

[61] Verda V, Guelpa E. Metodi termodinamici per l'uso efficiente delle risorse energetiche. Società Editrice Esculapio; 2013.

[62] Kyaw K, Kubota M, Watanabe F, Matsuda H, Hasatani M. Study of Carbonation of CaO for High Temperature Thermal Energy Storage. J Chem Eng JAPAN 1998;31:281-4. doi:10.1252/jcej.31.281

[63] Barin I. Thermochemical data of pure substances VCH, Weinheim (1989) 1989.

[64] Sun P, Grace JR, Lim CJ, Anthony EJ. Determination of intrinsic rate constants of the CaO-CO2 reaction. Chem Eng Sci 2008;63:47-56. doi:10.1016/j.ces.2007.08.055.

[65] Grasa GS, Abanades JC. CO2 Capture Capacity of $\mathrm{CaO}$ in Long Series of Carbonation/Calcination Cycles. Ind Eng Chem Res 2006;45:8846-51. doi:10.1021/ie0606946.

[66] Valverde JM. A model on the $\mathrm{CaO}$ multicyclic conversion in the Ca-looping process. Chem Eng J 2013;228:1195-206. doi:10.1016/j.cej.2013.05.023.

[67] U.S.DOE. SUNSHOT PROGRAM n.d. http://energy.gov/eere/sunshot/concentrating- 
solar-power.

\section{Figures captions}

Figure 1: Schematic representation of the CSP-CaL integration model with values of temperature, pressure, mass flow rate and composition in key stages (a $100 \mathrm{MW}_{\text {th }}$ CSP tower plant is considered).

Figure 2: Possible thermal coupling scheme between C1 and T2 (see Fig. 1) by means of an external IC+RH exchanger. $\mathrm{RH}$ : initial pre-heating to $50^{\circ} \mathrm{C}(1-2)$ and multistage expansion with re-heating stages up to $40^{\circ} \mathrm{C}$. IC: cooling up to $30^{\circ} \mathrm{C}$. a) Schematics b) Composite curves c) Processes on the PH diagram. 
Figure 3: Mass-balance schematics of the plant showing the flow rates of solids and $\mathrm{CO}_{2}$ streams between the carbonator and calciner.

Figure 4: $\mathrm{CO}_{2}$ storage conditions by considering a $12 \mathrm{~h}$ daytime (100 $\mathrm{MW}_{\text {th }}$ CSP plant).

Figure 5: Available heat of carbonation (left axis) and $\mathrm{CO}_{2}$ mass flow rate through the carbonator (right axis) vs $\mathrm{CaO}$ conversion

Figure 6: a) Thermal capacity of streams $\left(\mathrm{CaO}, \mathrm{CaCO}_{3}\right.$, and $\left.\mathrm{CO}_{2}\right)$ in the carbonator side heat exchangers (HXE, HXF, HXG, HXI) vs $\mathrm{CaO}$ conversion for a pressure ratio $\mathrm{PR}=3.2$. b) Efficiency vs $\mathrm{CaO}$ conversion (using $\mathrm{PR}=3.2$ ) for selected absolute pressures of the carbonator and turbine outlet, respectively, as indicated.

Figure 7: Variation of temperatures in the regions encircled in the diagram (according to the colors code) with pressure ratio.

Figure 8: Minimum value of $\mathrm{CaO}$ conversion for carbonator isothermal operation vs pressure ratio.

Figure 9: a) $\mathrm{CO}_{2}$ reaction turbine $-\mathrm{CO}_{2}$ cycle compression group. b) Left axis: Specific work of compression vs pressure ratio $P R$ for several turbine outlet pressures (TOP). TOP=0.1 bar (dashed line) and 1.3 bar (solid line). Right axis: $\mathrm{CO}_{2}$ mass flow rate vs PR.

Figure 10: a) Power balance in the $\mathrm{T} 2 / \mathrm{C} 1$ group. Net power consumption (carbonator side) vs pressure ratio for different values of turbine outlet pressure (shaded scale, where arrows direction represents higher TOP values). Solid curves refer to atmospheric turbine output 
pressure. b) Power balance in the carbonator side. Net power consumption, power generation in the turbine and net power production vs pressure ratio for different values of turbine outlet pressure are shown. A constant value of $\mathrm{CaO}$ conversion $\mathrm{X}=0.5$ is used.

Figure 11: Plant efficiency as a function of carbonator to turbine outlet pressures ratio (for a fixed $\mathrm{CaO}$ conversion $\mathrm{X}=0.5$ ) and turbine outlet pressure TOP (shaded scaling). The solid line corresponds to TOP=1 bar.

Figure 12: Contour plot of efficiency (assuming a constant value of $\mathrm{CaO}$ conversion $\mathrm{X}=0.5$ ) as depending on carbonator and turbine outlet pressure. Black lines indicate a constant value of pressure ratio.

Figure 13: Influence of pressure drops of $\mathrm{CO}_{2}$ in the circuit on efficiency as a function of pressure ratio PR. Maximum efficiency is decreased and the optimum pressure ratio is increased. Turbine outlet pressure $=1$ bar, $\mathrm{CaO}$ conversion $\mathrm{X}=0.5$.

Figure 14: a) Left axis: Carbonator capture efficiency vs temperature in the case of fully achieved carbonation (blue curve) and equilibrium capture efficiency (black curve) for carbonator pressures of $\mathbf{3 . 2}$ (solid line) and $\mathbf{8}$ (dotted line) bar (fixed pressure ratio PR= 3.2). Right axis: equilibrium and inlet molar fraction of $\mathrm{CO}_{2}$ vs temperature. b) $\mathrm{CO}_{2}$ molar flow rate through the carbonator vs carbonation temperature. Note that pure $\mathrm{CO}_{2}$ is used in the carbonator as working fluid ( $\mathrm{y}_{\mathrm{co} 2, \mathrm{carb}}$ in $=1$ as represented by the top red line).

Figure 15: Efficiency as a function of PR for different values of carbonation temperature and turbine outlet pressure. Red curve: turbine outlet pressure=1 bar, carbonation temperature $=875^{\circ} \mathrm{C}$; operation point (max efficiency): carbonator pressure=3.2 bar $(\mathrm{PR}=3.2$ ). Purple 
curve: turbine outlet pressure $=4 \mathrm{bar}$, carbonation temperature $=950^{\circ} \mathrm{C}$; operation point: carbonator pressure=14.8 bar $(\mathrm{PR}=3.7)$. The dashed part of the curves corresponds to $\mathrm{CO}_{2}$ equilibrium molar fraction>0.3. It can be seen that working at the optimum point with higher absolute pressures enhances efficiency through a temperature upgrade.

Figure 16: Efficiency as a function of PR for different values of the carbonation temperature. Red curve: turbine outlet pressure $=1$ bar, carbonation temperature $=875^{\circ} \mathrm{C}$; operation point: carbonator pressure=3.2 bar (PR=3.2). Blue curve: turbine outlet pressure=1 bar, carbonation temperature $=950^{\circ} \mathrm{C}$; operation point: carbonator pressure=9.2 bar $(P R=9.2)$. The dashed part of the curves corresponds to $\mathrm{CO}_{2}$ equilibrium molar fraction>0.3. The horizontal arrow shows that working at higher pressure ratios is possible without penalizing efficiency through a temperature upgrade.

Figure 17: Multicycle conversion of limestone derived $\mathrm{CaO}$ as obtained from thermogravimetric analysis (TGA) tests under different CaL conditions (reported in [44]). CSP storage conditions: carbonation at $850 \circ \mathrm{C}$ under pure $\mathrm{CO}_{2}$ and calcination at $700 \circ \mathrm{C}$ under pure $\mathrm{He} . \mathrm{CO}_{2}$ capture conditions: Carbonation at $650 \circ \mathrm{C}$ under a $15 \% \mathrm{CO}_{2} / 85 \%$ air vol/vol atmosphere and calcination at 950 - $\mathrm{C}$ under a $70 \% \mathrm{CO}_{2} / 30 \%$ air vol/vol atmosphere. Residence times at both stages were 5 min. The solid lines are best fits from Eq. 10 to data.

Figure 18: Efficiency variation derived from a sensitivity analysis on ambient temperature, heat exchangers and solar daylight hours using as reference values those shown in Table 3.

Figure 19: Efficiency variation derived from a sensitivity analysis on carbonator thermal dispersion, system transport and storage pressure using as reference values those shown in Table 3. 



\section{Tables Captions}

Table 1: Energy density and turning temperature of various thermochemical energy storage systems. Adapted from [16].

Table 2: Main simulation model data

Table 3: Sensitivity Analysis Data 


\section{Tables}

Error! Reference source not found.

\begin{tabular}{|c|c|c|}
\hline $\begin{array}{c}\text { Thermochemical energy } \\
\text { storage systems }\end{array}$ & $\begin{array}{c}\text { Turning } \\
\text { temperature (oC) }\end{array}$ & $\begin{array}{c}\text { Energy } \\
\text { density }\left(\mathbf{M J} / \mathbf{m}^{3} \text { ) }\right.\end{array}$ \\
\hline $\mathrm{NH}_{3} / \mathrm{N}_{2}$ & 195 & 131 \\
\hline $\mathrm{CH}_{4} / \mathrm{H}_{2} \mathrm{O}$ & 688 & 223 \\
\hline $\mathrm{SO}_{3} / \mathrm{SO}_{2}$ & 782 & 459 \\
\hline $\mathrm{CaO} / \mathrm{H}_{2} \mathrm{O}$ & 479 & 1967 \\
\hline $\mathrm{Li}_{2} \mathrm{O} / \mathrm{H}_{2} \mathrm{O}$ & 731 & 2216 \\
\hline $\mathrm{NH}_{4} \mathrm{HSO}_{4} / \mathrm{NH}_{3}$ & 467 & 3082 \\
\hline $\mathrm{CaO} / \mathrm{CO}_{2}$ & 895 & 3226 \\
\hline $\mathrm{SrO} / \mathrm{CO}_{2}$ & 1108 & 3948 \\
\hline
\end{tabular}


Error! Reference source not found. used in our work to simulate the proposed CSP-CaL

integration model

\begin{tabular}{|cc|}
\hline Net absorbed solar flux in calciner & $100 \mathrm{MWt}$ \\
\hline Daylight hours (constant solar flux) & 12 \\
\hline Thermal dispersions in carbonator & $10 \%$ \\
\hline Calciner temperature & $900^{\circ} \mathrm{C}$ \\
\hline Carbonator temperature & $875^{\circ} \mathrm{C}$ \\
\hline Carbonator pressure & $3.2 \mathrm{bar}$ \\
\hline Turbine outlet pressure & $1 \mathrm{bar}$ \\
\hline Ambient temperature & $20^{\circ} \mathrm{C}$ \\
\hline Minimum temperature difference solid-solid $\mathrm{HX}$ & $20^{\circ} \mathrm{C}$ \\
\hline Minimum temperature difference solid-gas $\mathrm{HX}$ & $15^{\circ} \mathrm{C}$ \\
\hline Minimum temperature difference gas-gas $\mathrm{HX}$ & $15^{\circ} \mathrm{C}$ \\
\hline Minimum temperature difference CO ${ }_{2}$ cooler & $10^{\circ} \mathrm{C}$ \\
\hline Intercoolings in CO ${ }_{2}$ storage compression & 5 \\
\hline Intercoolings in power cycle compression & 2 \\
\hline Pressure losses in CO ${ }_{2}$ circuit & $0 \mathrm{bar}$ \\
\hline $\mathrm{CO}_{2}$ storage conditions & $75 \mathrm{bar}, \mathrm{T}$ ambient \\
\hline Solid phase conveying energy consumption & $10 \mathrm{MJ} /$ tonne/ $/ 100 \mathrm{~m}$ \\
\hline Equivalent length solids conveying carbonator side & $100 \mathrm{~m}$ \\
\hline Equivalent length solids conveying calciner side & $100 \mathrm{~m}$ \\
\hline Isentropic efficiencies (compression/expansion) & 0.89 \\
\hline
\end{tabular}


Error! Reference source not found.

\begin{tabular}{|c|c|c|c|c|c|}
\hline Parameter & $\begin{array}{c}\text { Sensitivity } \\
\text { on }\end{array}$ & Ref. value & \multicolumn{3}{|c|}{ Range of variation } \\
\hline $\begin{array}{c}\text { Ambient } \\
\text { temperature }\end{array}$ & $\begin{array}{l}\text { Storage } \\
\text { volume }\end{array}$ & $20^{\circ} \mathrm{C}$ & $0^{\circ} \mathrm{C}$ & $\div$ & $40^{\circ} \mathrm{C}$ \\
\hline $\begin{array}{l}\text { Carbonator thermal } \\
\text { dispersions (\% of } \\
\text { carbonator thermal } \\
\text { power production) }\end{array}$ & Efficiency & $10 \%$ & $2 \%$ & $\div$ & $15 \%$ \\
\hline $\begin{array}{l}\mathrm{CO}_{2} \text { storage } \\
\text { pressure }\end{array}$ & Efficiency & 75 bar & 50 bar & $\div$ & 120 bar \\
\hline $\begin{array}{c}\text { Minimum } \\
\text { temperature } \\
\text { difference solid- } \\
\text { solid exchangers }\end{array}$ & Efficiency & $20^{\circ} \mathrm{C}$ & $10^{\circ} \mathrm{C}$ & $\div$ & $30^{\circ} \mathrm{C}$ \\
\hline $\begin{array}{c}\text { Minimum } \\
\text { temperature } \\
\text { difference gas-solid } \\
\text { exchangers }\end{array}$ & Efficiency & $15^{\circ} \mathrm{C}$ & $5^{\circ} \mathrm{C}$ & $\div$ & $25^{\circ} \mathrm{C}$ \\
\hline $\begin{array}{c}\text { Minimum } \\
\text { temperature } \\
\text { difference gas-gas } \\
\text { exchangers }\end{array}$ & Efficiency & $15^{\circ} \mathrm{C}$ & $5^{\circ} \mathrm{C}$ & $\div$ & $25^{\circ} \mathrm{C}$ \\
\hline $\begin{array}{l}\text { Pressure drops in } \\
\text { carbonator circuit } \\
\text { (\% of carbonator } \\
\text { pressure) }\end{array}$ & Efficiency & $0 \%$ & $0 \%$ & $\div$ & $20 \%$ \\
\hline $\begin{array}{c}\text { Conveying } \\
\text { consumption factor }\end{array}$ & Efficiency & $10 \mathrm{MJ} / 100 \mathrm{~m} /$ tonne & $3 \mathrm{MJ} / 100 \mathrm{~m} /$ tonne & $\div$ & $18 \mathrm{MJ} / 100 \mathrm{~m} /$ tonne \\
\hline $\begin{array}{c}\text { Total solid } \\
\text { conveying } \\
\text { equivalent distance }\end{array}$ & Efficiency & $200 \mathrm{~m}$ & $50 \mathrm{~m}$ & $\div$ & $350 m$ \\
\hline Solar daylight hours & $\begin{array}{c}\text { Daily } \\
\text { electricity } \\
\text { production }\end{array}$ & $12 \mathrm{~h}$ & $6 \mathrm{~h}$ & $\div$ & $12 \mathrm{~h}$ \\
\hline
\end{tabular}




\section{Figures}

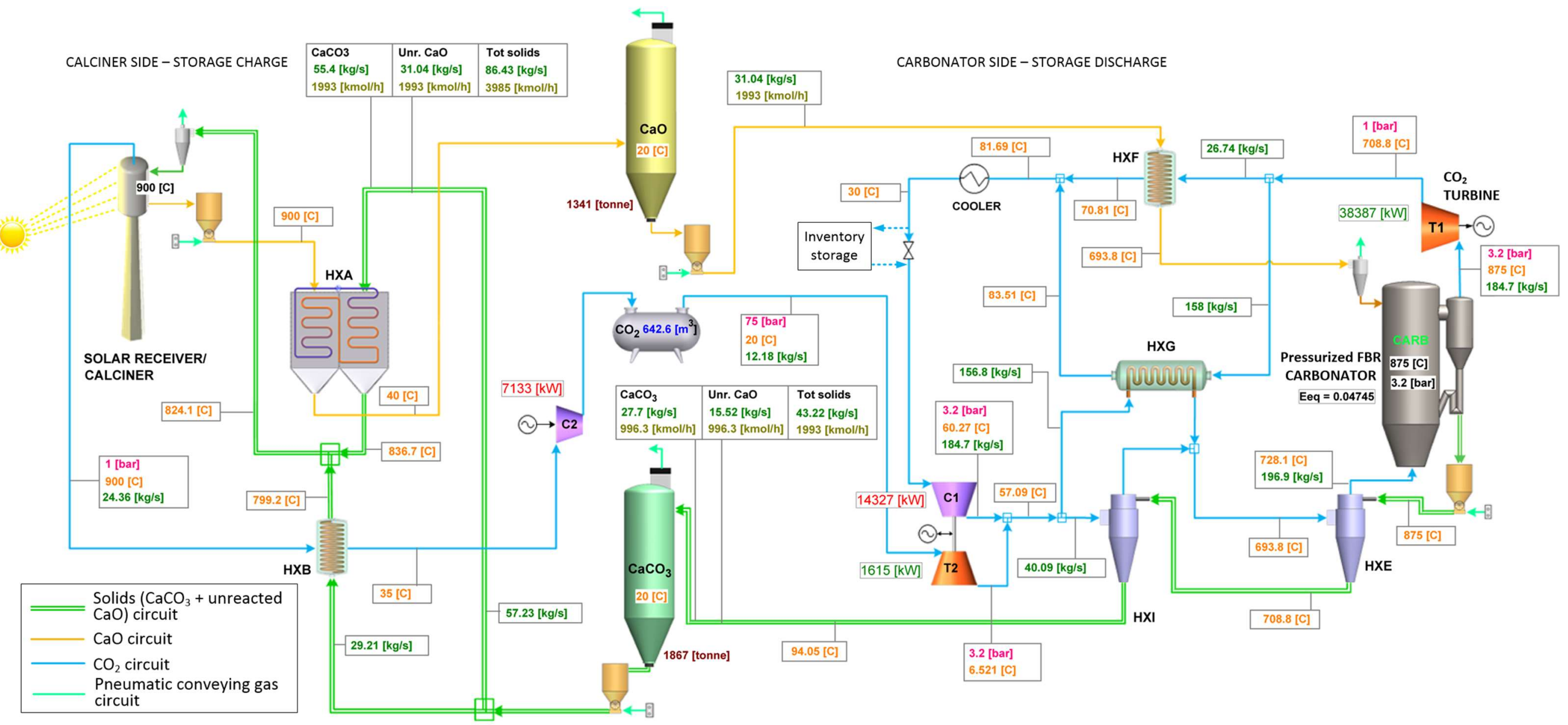

Figure 1: Schematic representation of the CSP-CaL integration model with values of temperature, pressure, mass flow rate and composition in key stages (a 100 $\mathrm{MW}_{\text {th }}$ CSP tower plant is considered). 


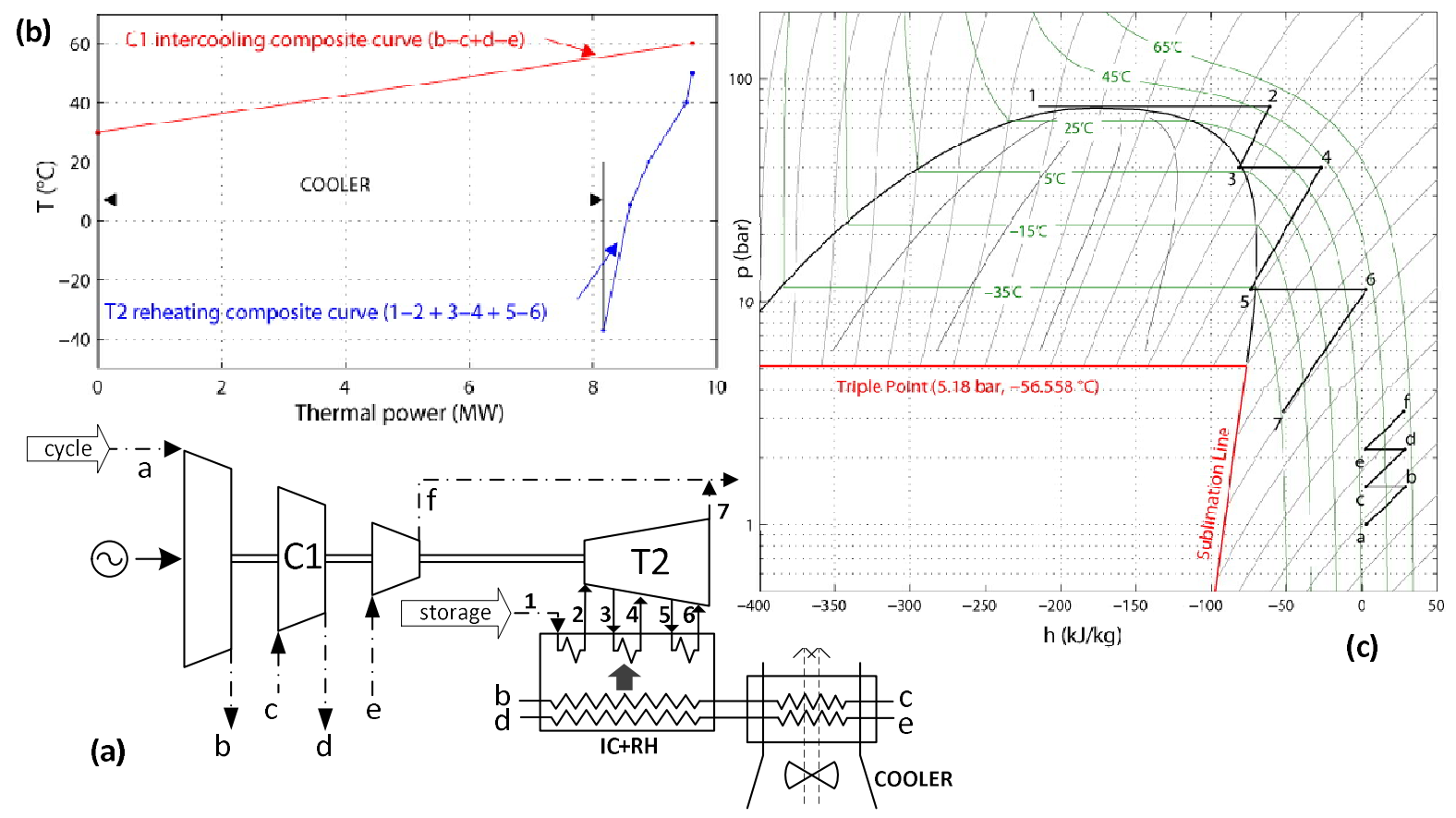

Figure 2: Possible thermal coupling scheme between $\mathrm{C} 1$ and T2 (see Fig. 1) by means of an external IC+RH exchanger. $\mathrm{RH}$ : initial pre-heating to $50^{\circ} \mathrm{C}(1-2)$ and multistage expansion with re-heating stages up to $40^{\circ} \mathrm{C}$. IC: cooling up to $30^{\circ} \mathrm{C}$. a) Schematics b) Composite curves c) Processes on the PH diagram. 


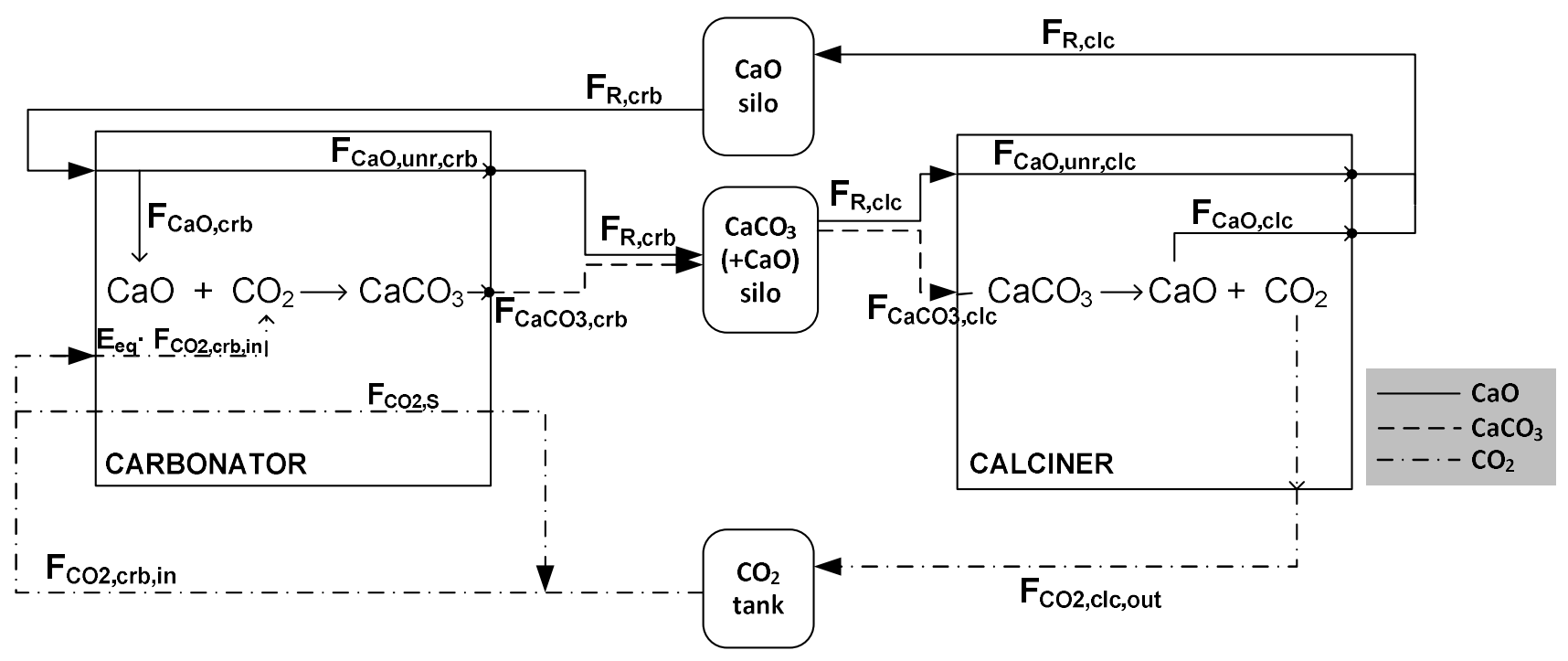

Figure 3: Mass-balance schematics of the plant showing the flow rates of solids and $\mathrm{CO}_{2}$ streams between the carbonator and calciner. 


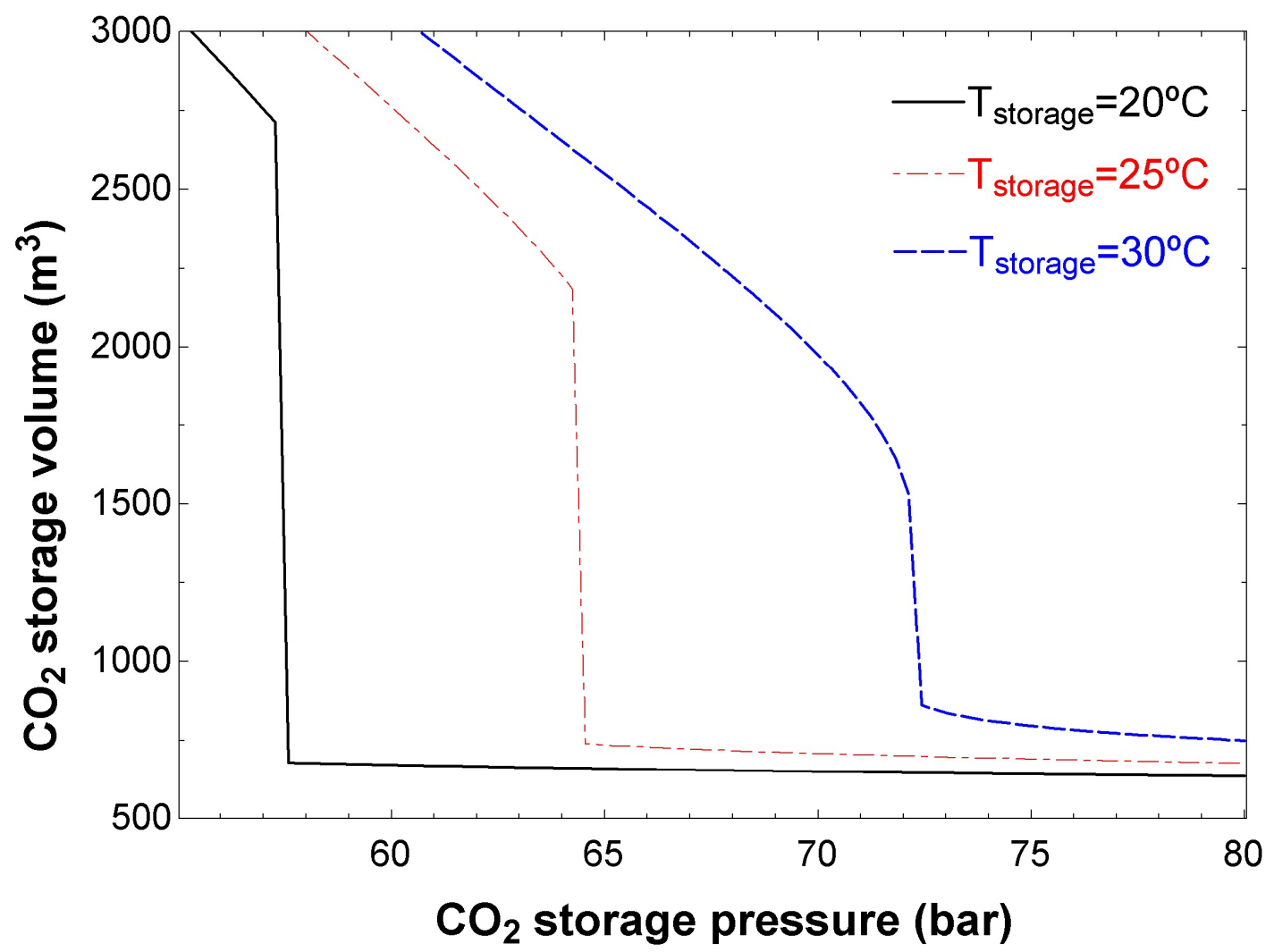

Figure 4: $\mathrm{CO}_{2}$ storage conditions by considering a $12 \mathrm{~h}$ daytime (100 $\mathrm{MW}_{\text {th }}$ CSP plant). 


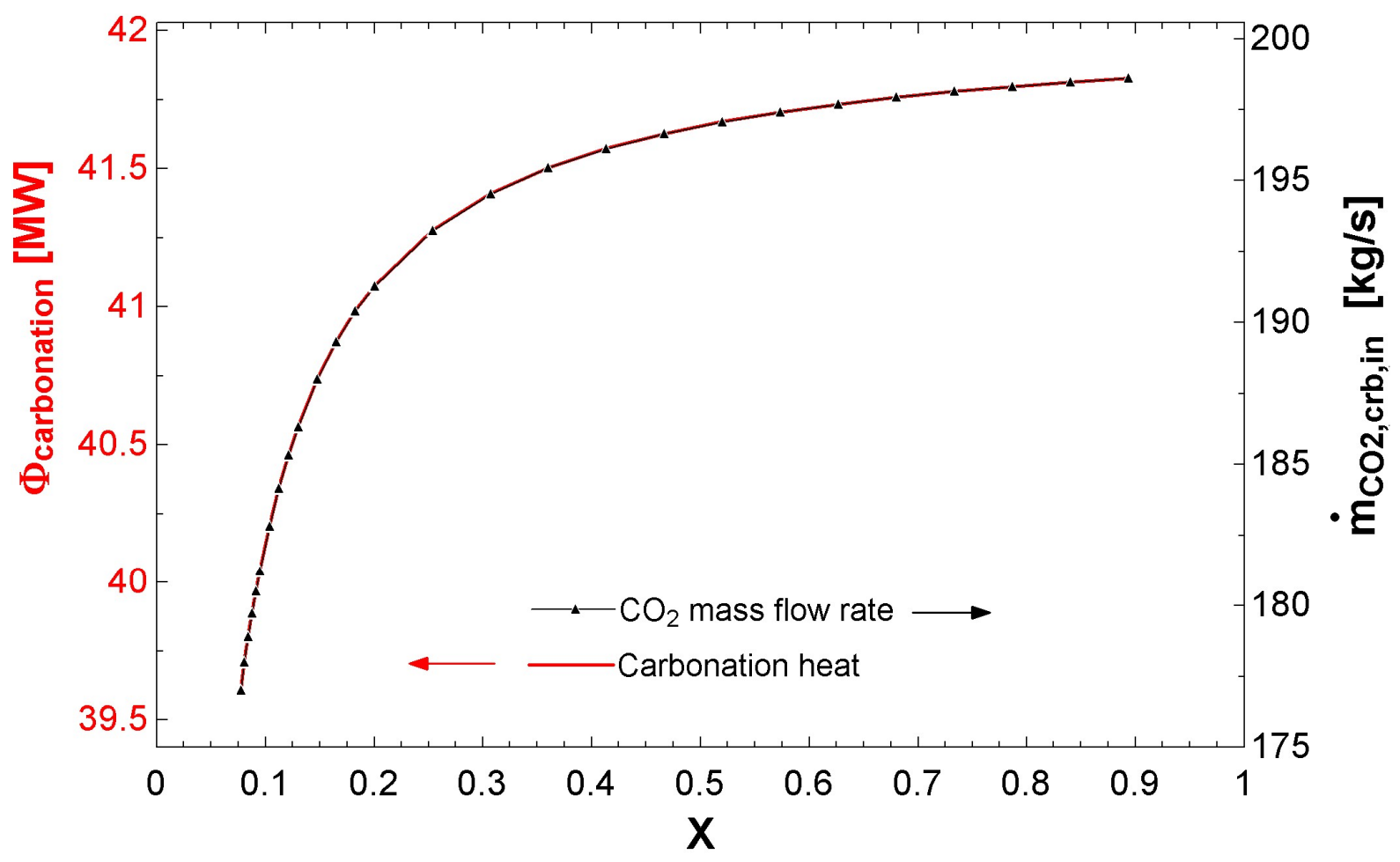

Figure 5: Available heat of carbonation (left axis) and $\mathrm{CO}_{2}$ mass flow rate through the carbonator (right axis) vs $\mathrm{CaO}$ conversion 

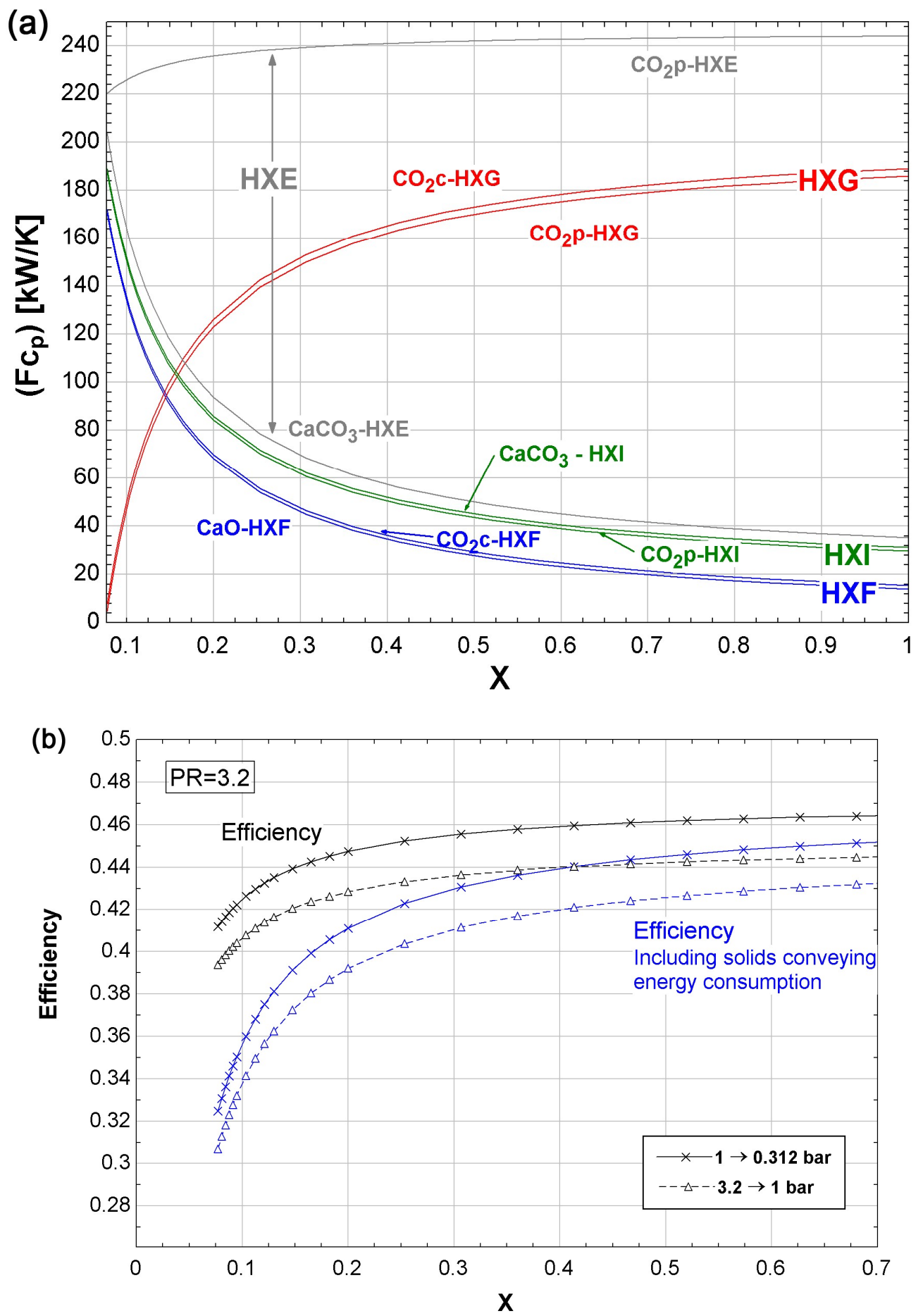

Figure 6: a) Thermal capacity of streams $\left(\mathrm{CaO}, \mathrm{CaCO}_{3}\right.$, and $\left.\mathrm{CO}_{2}\right)$ in the carbonator side heat exchangers ( $\mathrm{HXE}, \mathrm{HXF}, \mathrm{HXG}, \mathrm{HXI}$ ) vs $\mathrm{CaO}$ conversion for a pressure ratio $P R=3.2$. b) Efficiency vs $\mathrm{CaO}$ conversion (using $P R=3.2$ ) for selected absolute pressures of the carbonator and turbine outlet, respectively, as indicated. 

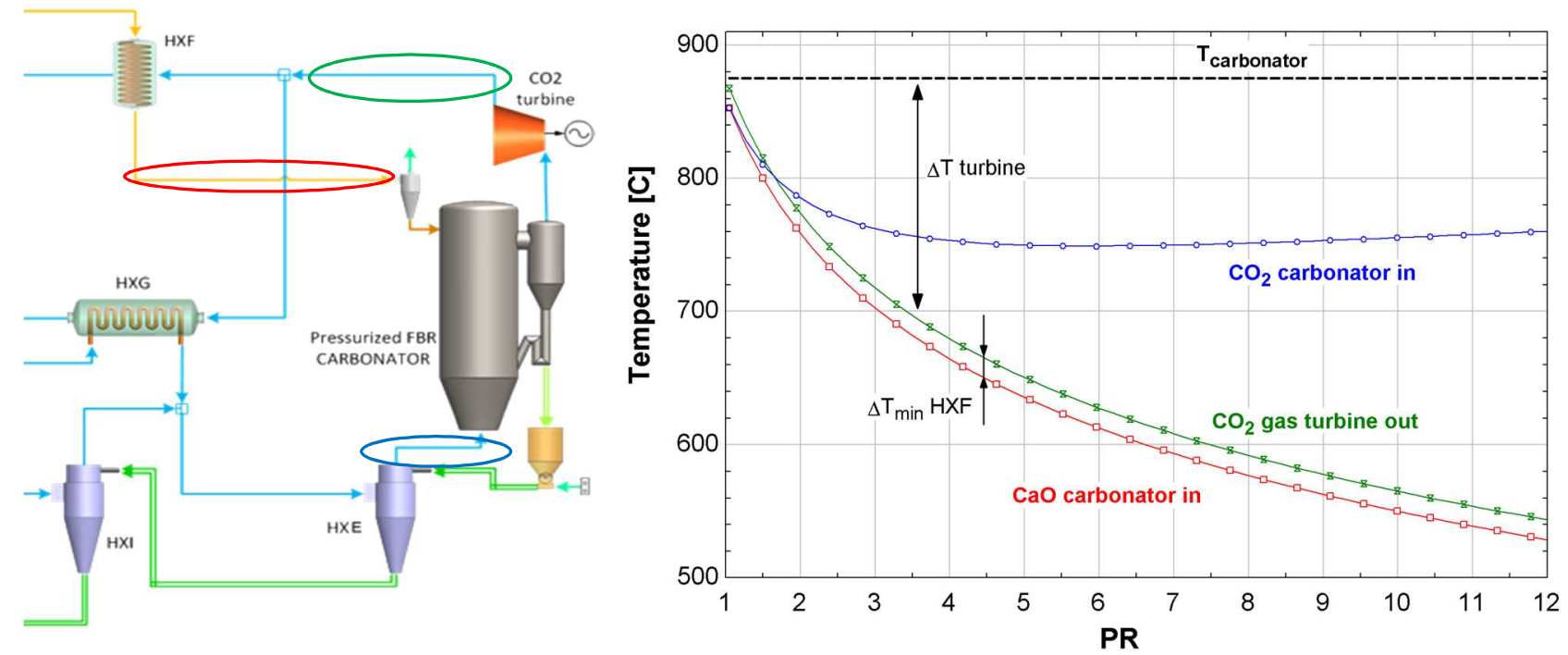

Figure 7: Variation of temperatures in the regions encircled in the diagram (according to the colors code) with pressure ratio. 


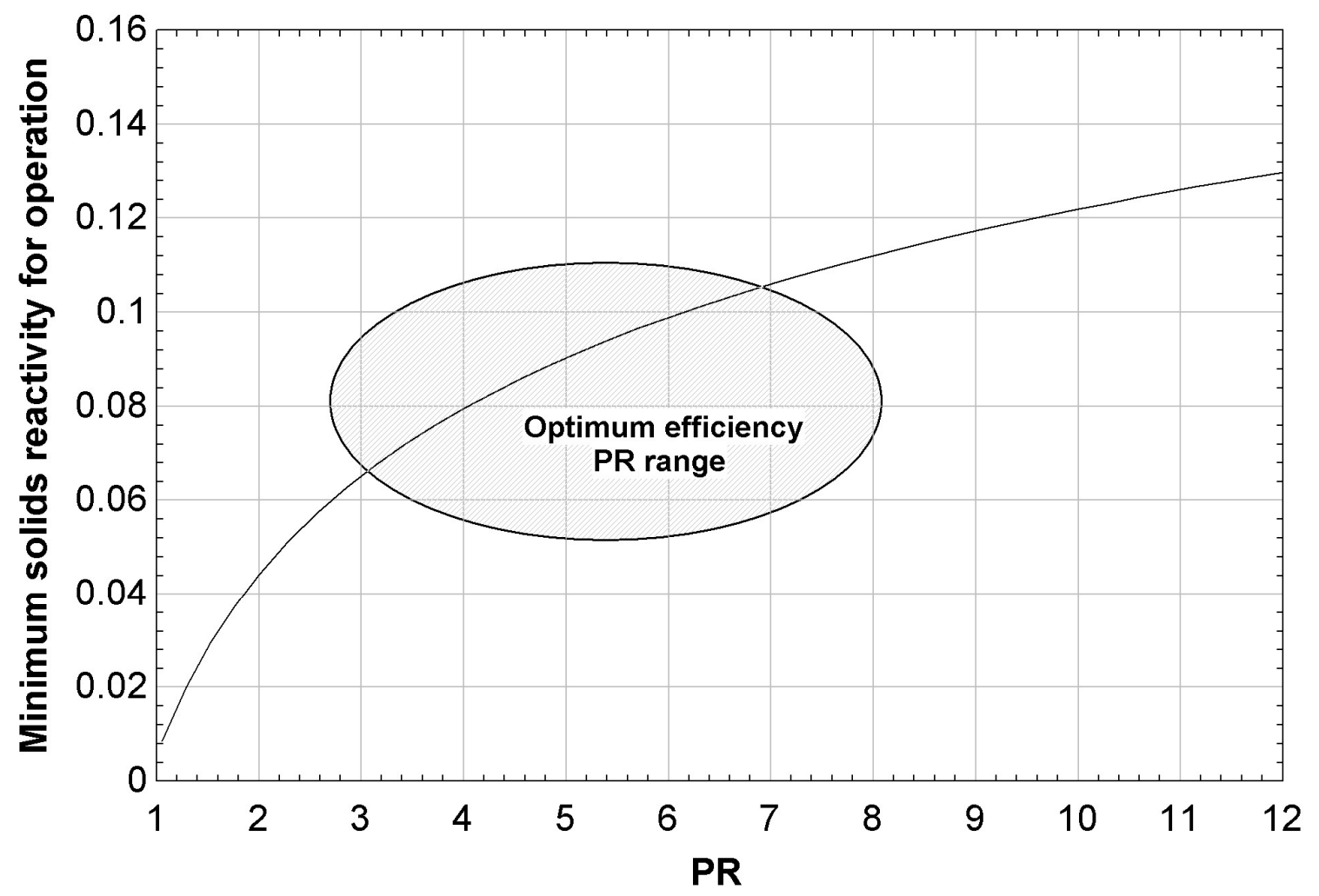

Figure 8: Minimum value of $\mathrm{CaO}$ conversion for carbonator isothermal operation vs pressure ratio. 
(a)

(b)
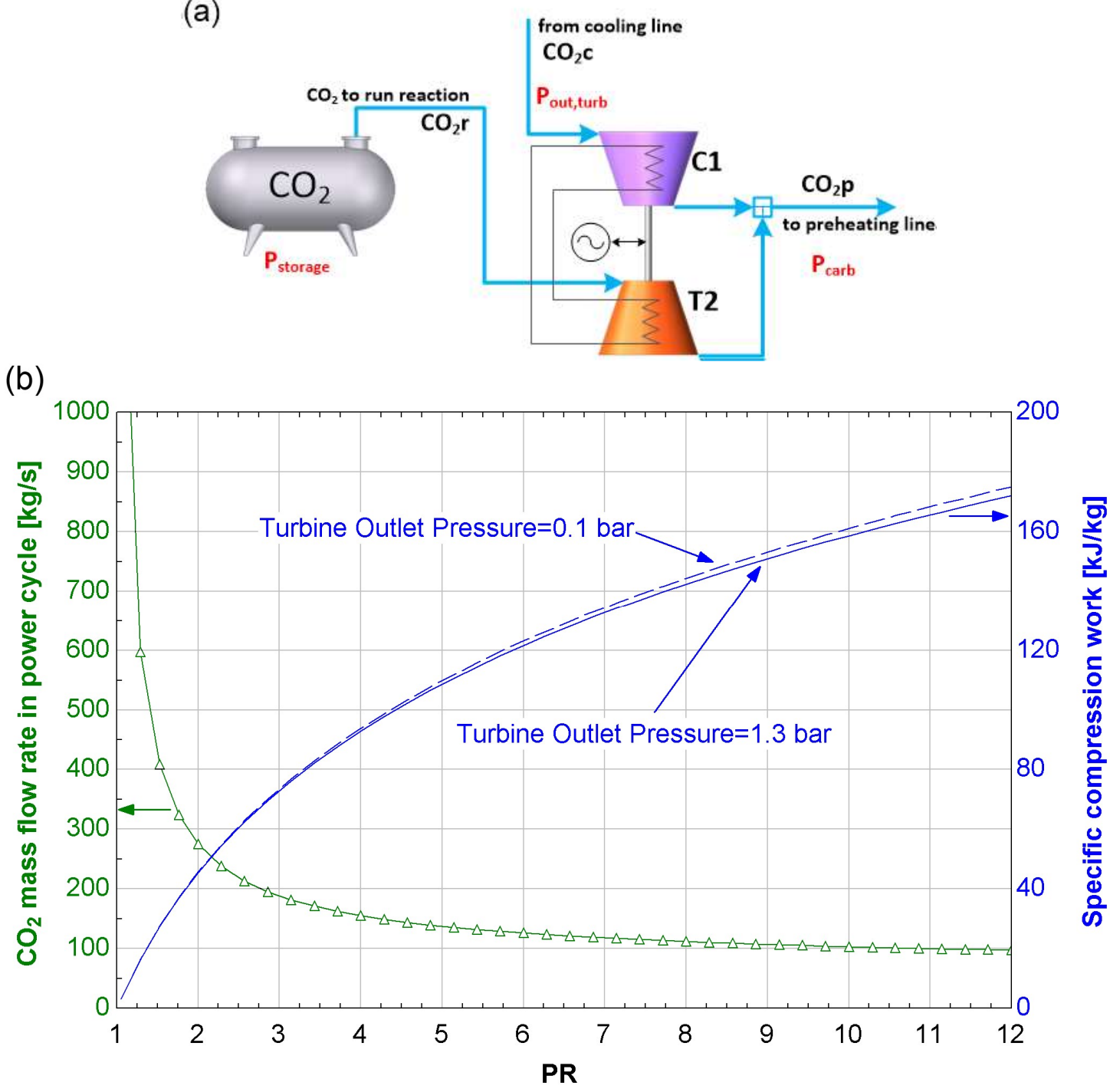

Figure 9: a) $\mathrm{CO}_{2}$ reaction turbine $-\mathrm{CO}_{2}$ cycle compression group. b) Left axis: Specific work of compression vs pressure ratio PR for several turbine outlet pressures (TOP). TOP=0.1 bar (dashed line) and 1.3 bar (solid line). Right axis: $\mathrm{CO}_{2}$ mass flow rate vs PR. 
(a)

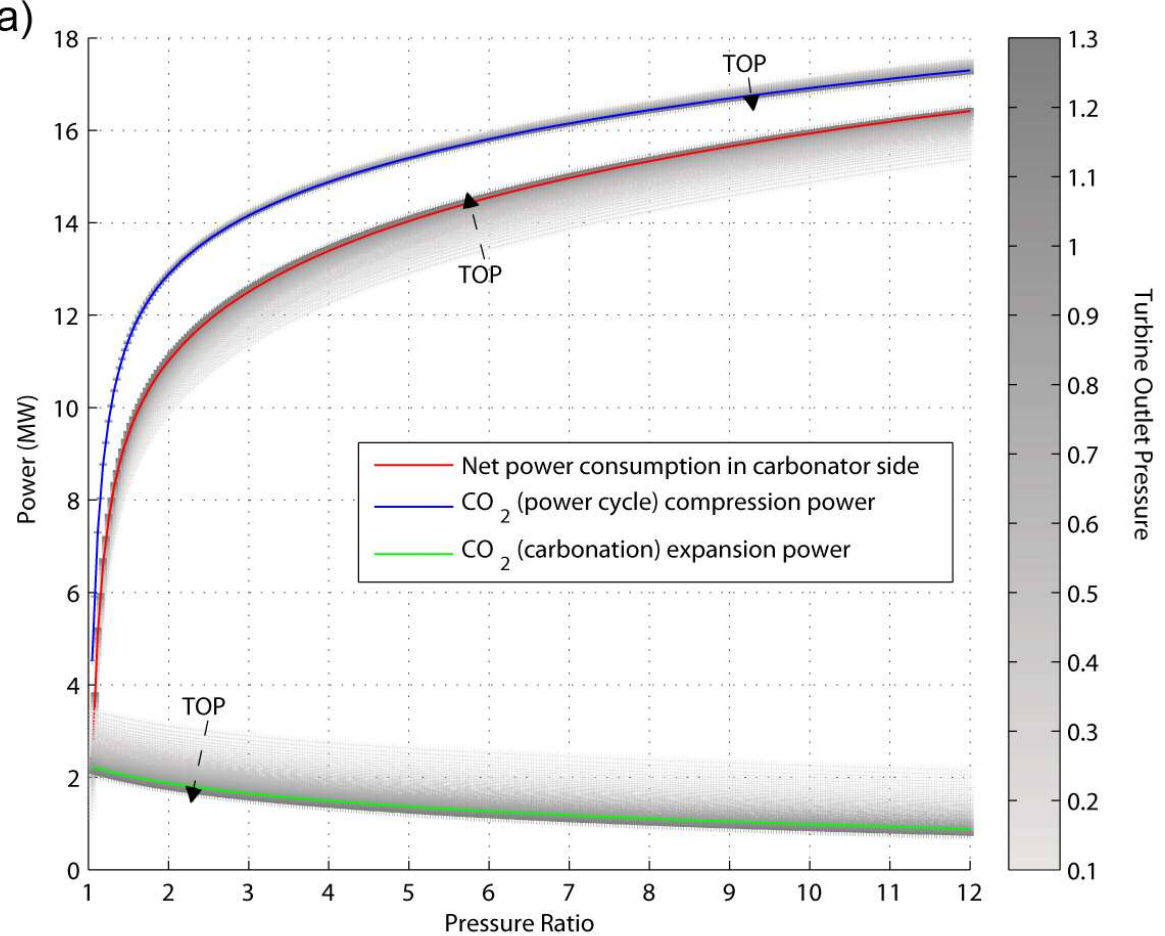

(b)
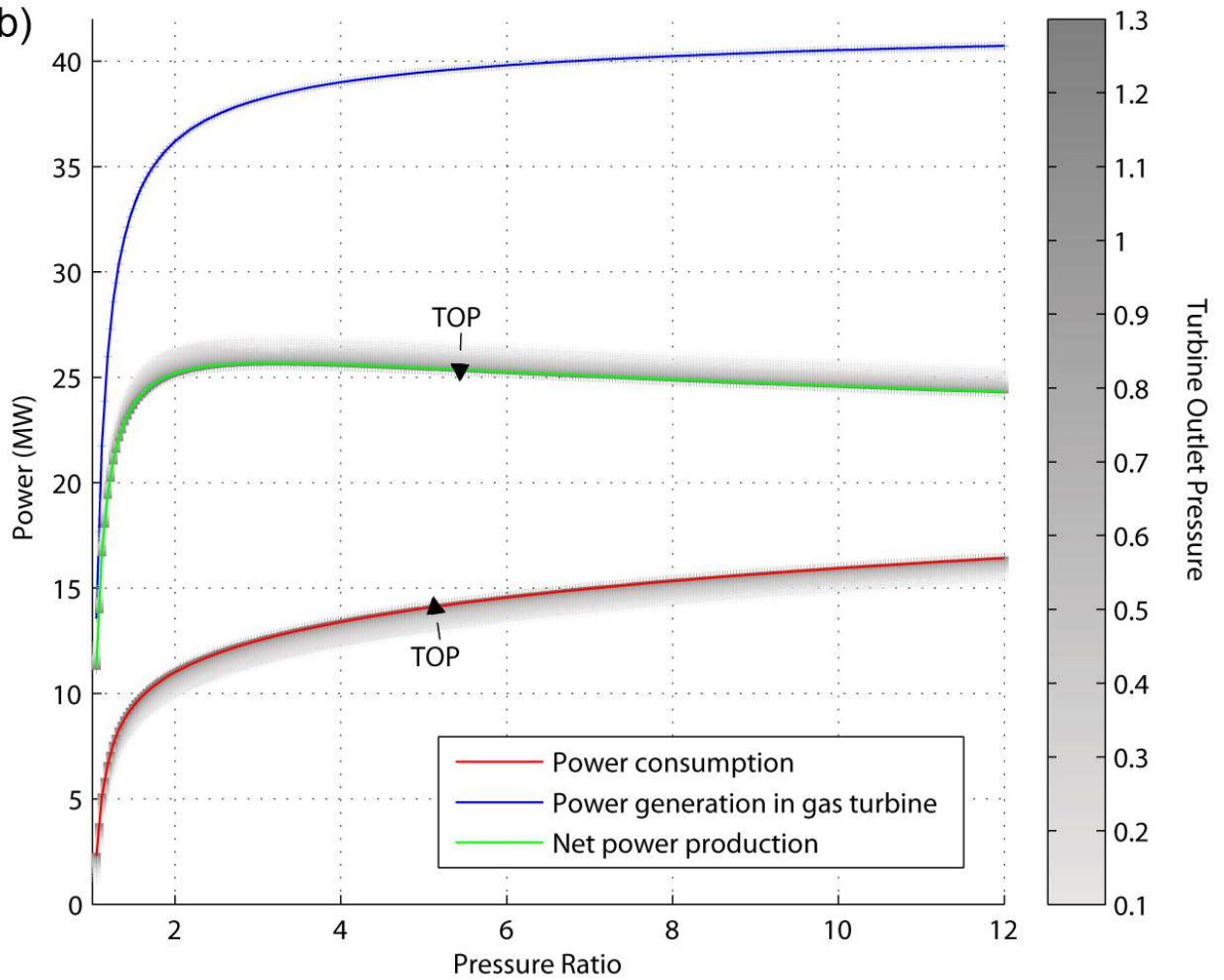

Figure 10: a) Power balance in the T2/C1 group. Net power consumption (carbonator side) vs pressure ratio for different values of turbine outlet pressure (shaded scale, where arrows direction represents higher TOP values). Solid curves refer to atmospheric turbine output pressure. b) Power balance in the carbonator side. Net power consumption, power generation in the turbine and net power production vs pressure ratio for different values of turbine outlet pressure are shown. A constant value of $\mathrm{CaO}$ conversion $\mathrm{X}=0.5$ is used. 


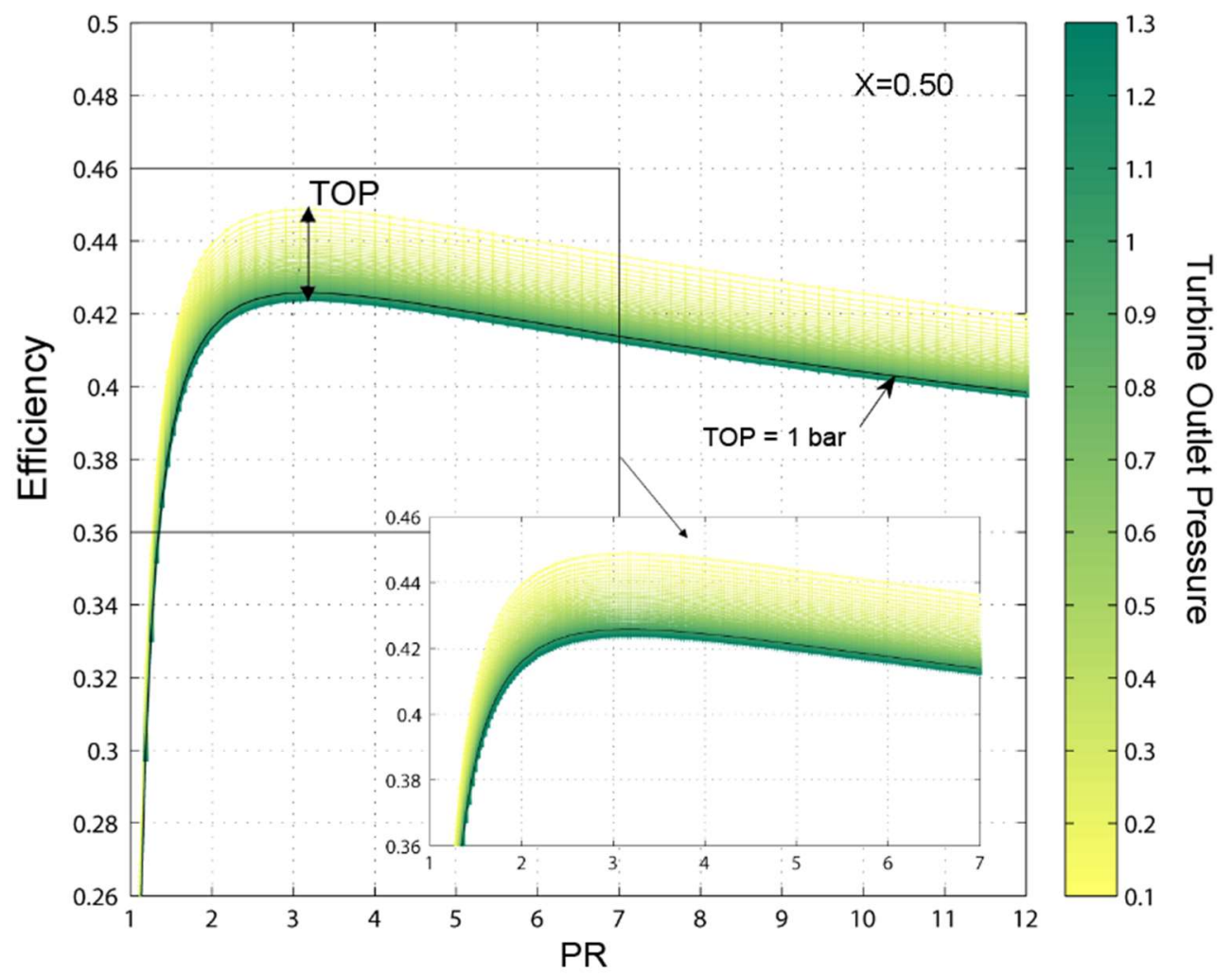

Figure 11: Plant efficiency as a function of carbonator to turbine outlet pressures ratio (for a fixed $\mathrm{CaO}$ conversion $\mathrm{X}=0.5$ ) and turbine outlet pressure TOP (shaded scaling). The solid line corresponds to TOP=1 bar. 


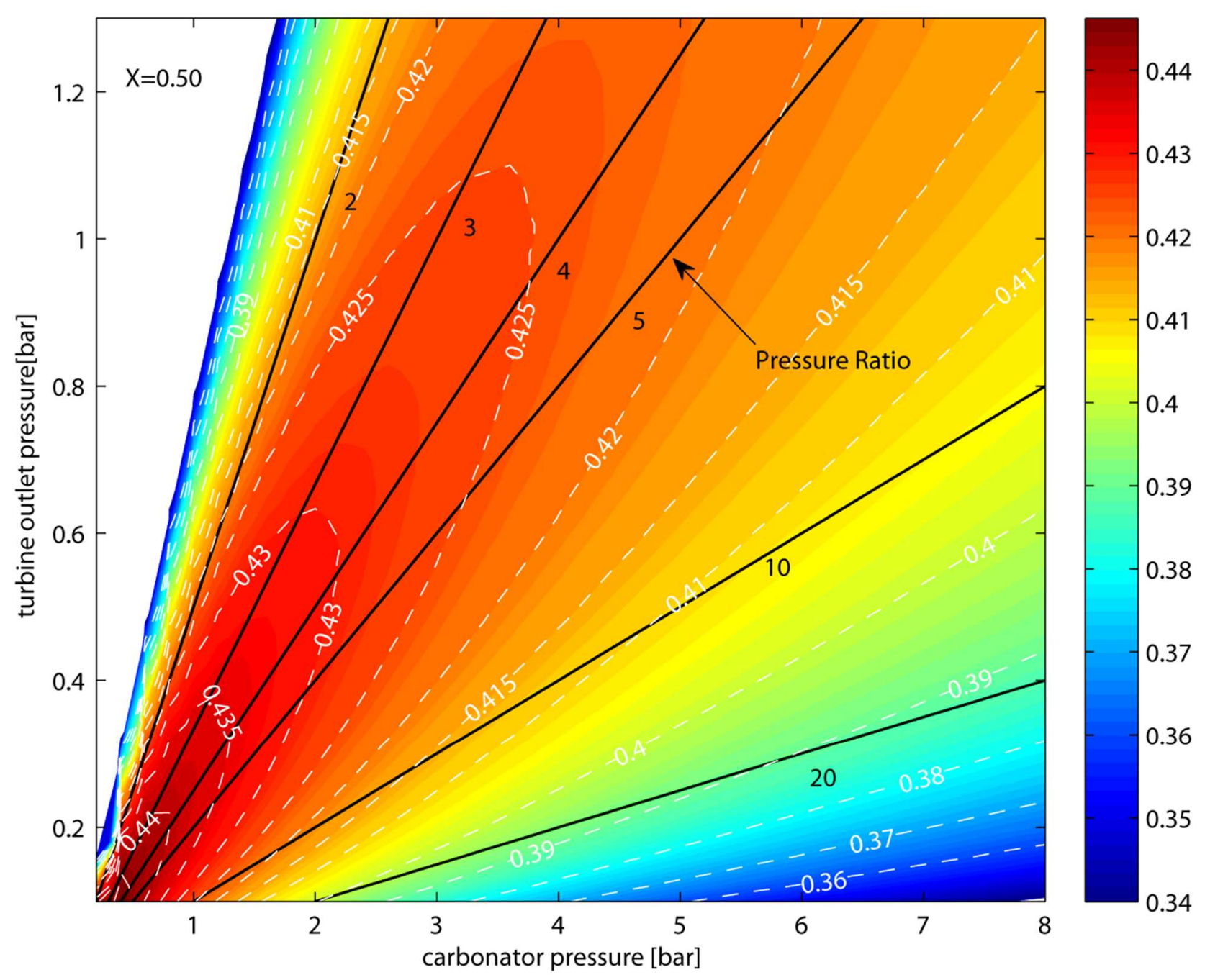

Figure 12: Contour plot of efficiency (assuming a constant value of $\mathrm{CaO}$ conversion $\mathrm{X}=0.5$ ) as depending on carbonator and turbine outlet pressure. Black lines indicate a constant value of pressure ratio. 


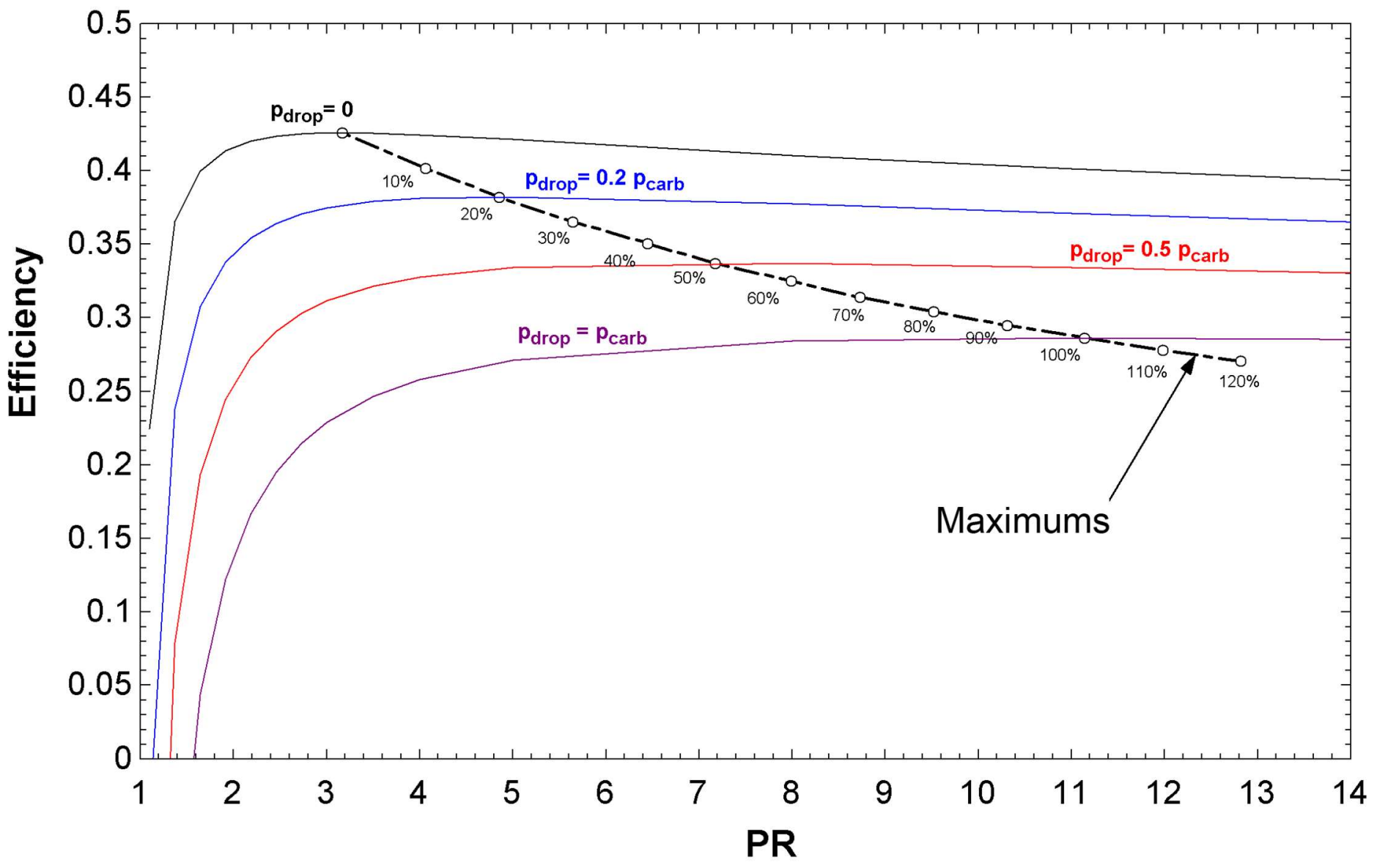

Figure 13: Influence of pressure drops of $\mathrm{CO}_{2}$ in the circuit on efficiency as a function of pressure ratio $P R$. Maximum efficiency is decreased and the optimum pressure ratio is increased. Turbine outlet pressure $=1$ bar, $\mathrm{CaO}$ conversion $\mathrm{X}=0.5$. 

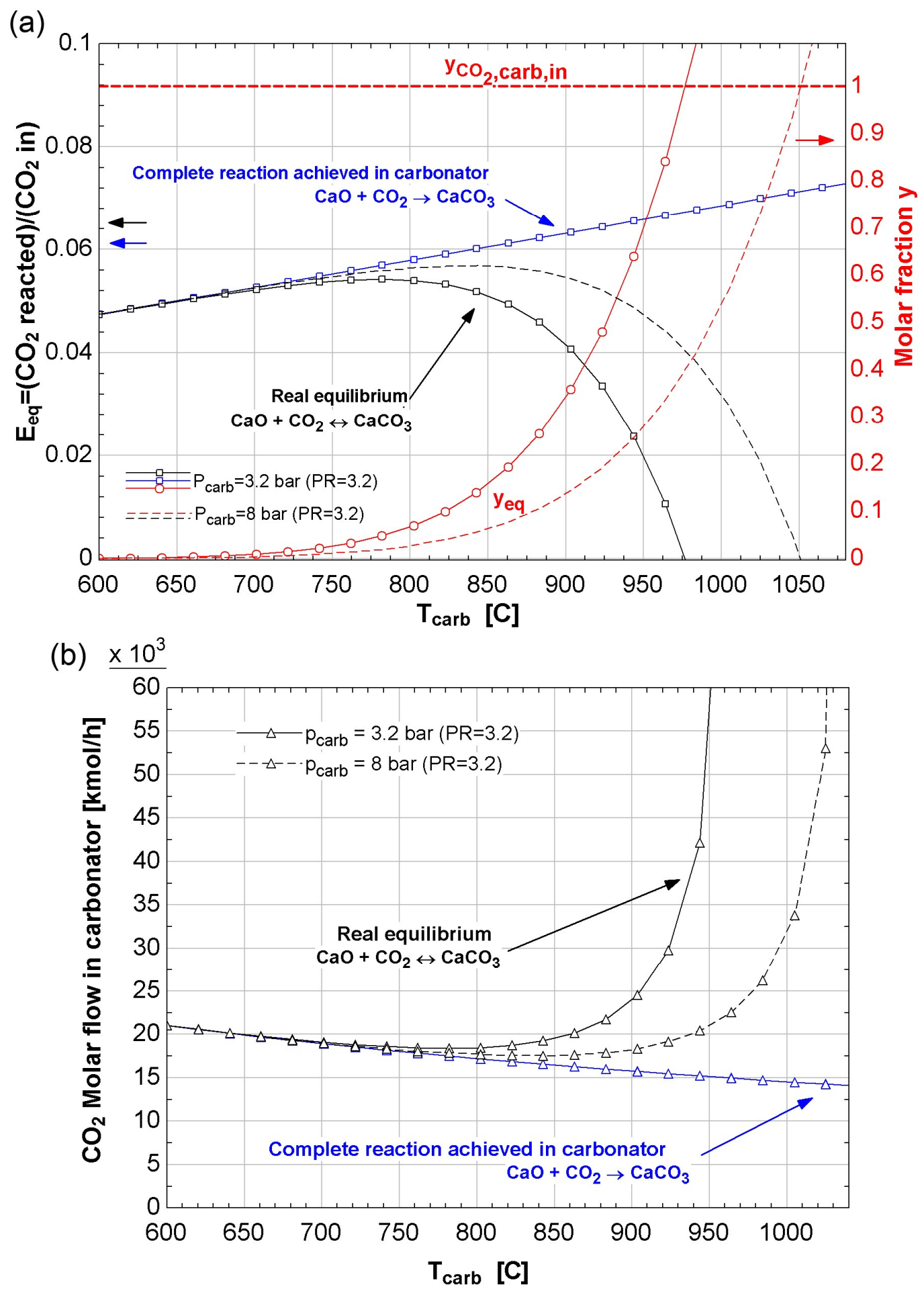

Figure 14: a) Left axis: Carbonator capture efficiency vs temperature in the case of fully achieved carbonation (blue curve) and equilibrium capture efficiency (black curve) for carbonator pressures of 3.2 (solid line) and 8 (dotted line) bar (fixed pressure ratio $P R=3.2$ ). Right axis: equilibrium and inlet molar fraction of $\mathrm{CO} 2$ vs temperature. b) $\mathrm{CO} 2$ molar flow rate through carbonator vs carbonation temperature. Note that pure $\mathrm{CO} 2$ is used in the carbonator as working fluid. (Note that pure $\mathrm{CO} 2$ is used in the carbonator as working fluid (yco2, carb, in = 1 as represented by the top red line). 


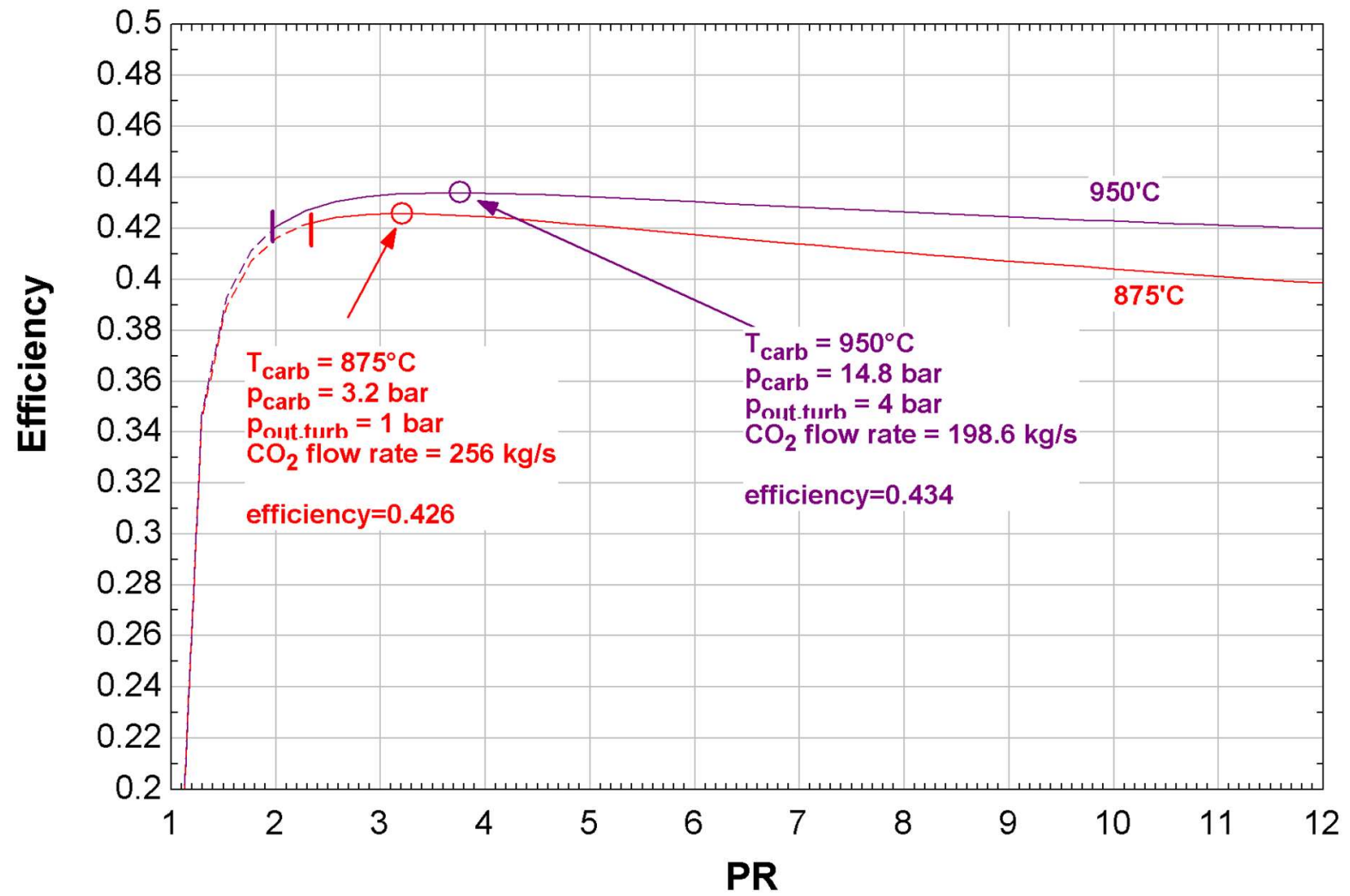

Figure 15: Efficiency as a function of PR for different values of carbonation temperature and turbine outlet pressure. Red curve: turbine outlet pressure $=1$ bar, carbonation temperature $=$ $875^{\circ} \mathrm{C}$; operation point (max efficiency): carbonator pressure=3.2 bar ( $P R=3.2$ ). Purple curve: turbine outlet pressure $=4$ bar, carbonation temperature $=950^{\circ} \mathrm{C}$; operation point: carbonator pressure=14.8 bar ( $P R=3.7)$. The dashed part of the curves corresponds to $\mathrm{CO} 2$ equilibrium molar fraction>0.3. It can be seen that working at the optimum point with higher absolute pressures enhances efficiency through a temperature upgrade. 


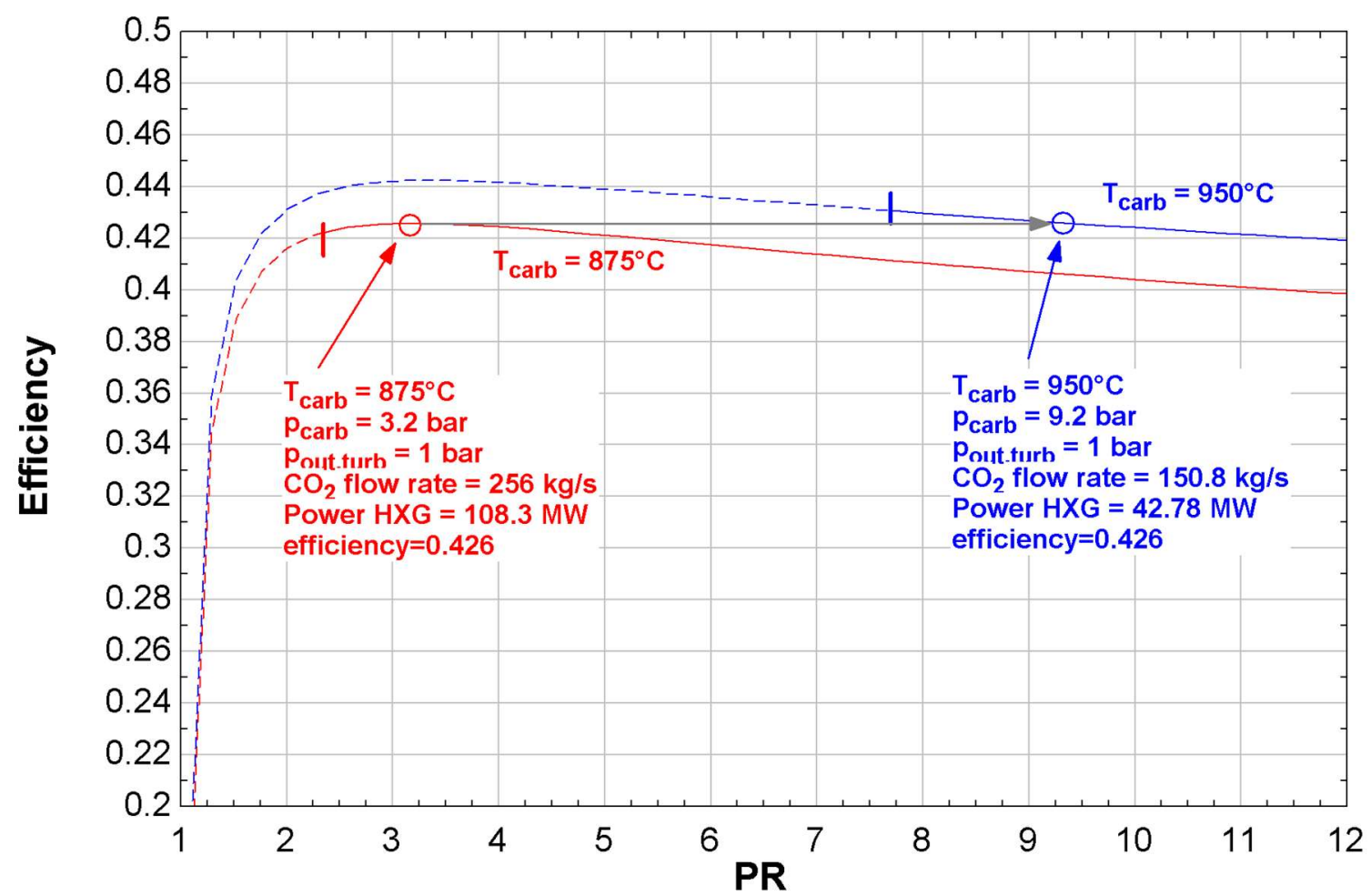

Figure 16: Efficiency as a function of PR for different values of the carbonation temperature. Red curve: turbine outlet pressure $=1$ bar, carbonation temperature $=875^{\circ} \mathrm{C}$; operation point: carbonator pressure=3.2 bar ( $P R=3.2)$. Blue curve: turbine outlet pressure=1 bar, carbonation temperature $=$ $950^{\circ} \mathrm{C}$; operation point: carbonator pressure $=9.2$ bar $(P R=9.2)$. The dashed part of the curves corresponds to $\mathrm{CO} 2$ equilibrium molar fraction $>0.3$. The horizontal arrow shows that working at higher pressure ratios is possible without penalizing efficiency through a temperature upgrade. 


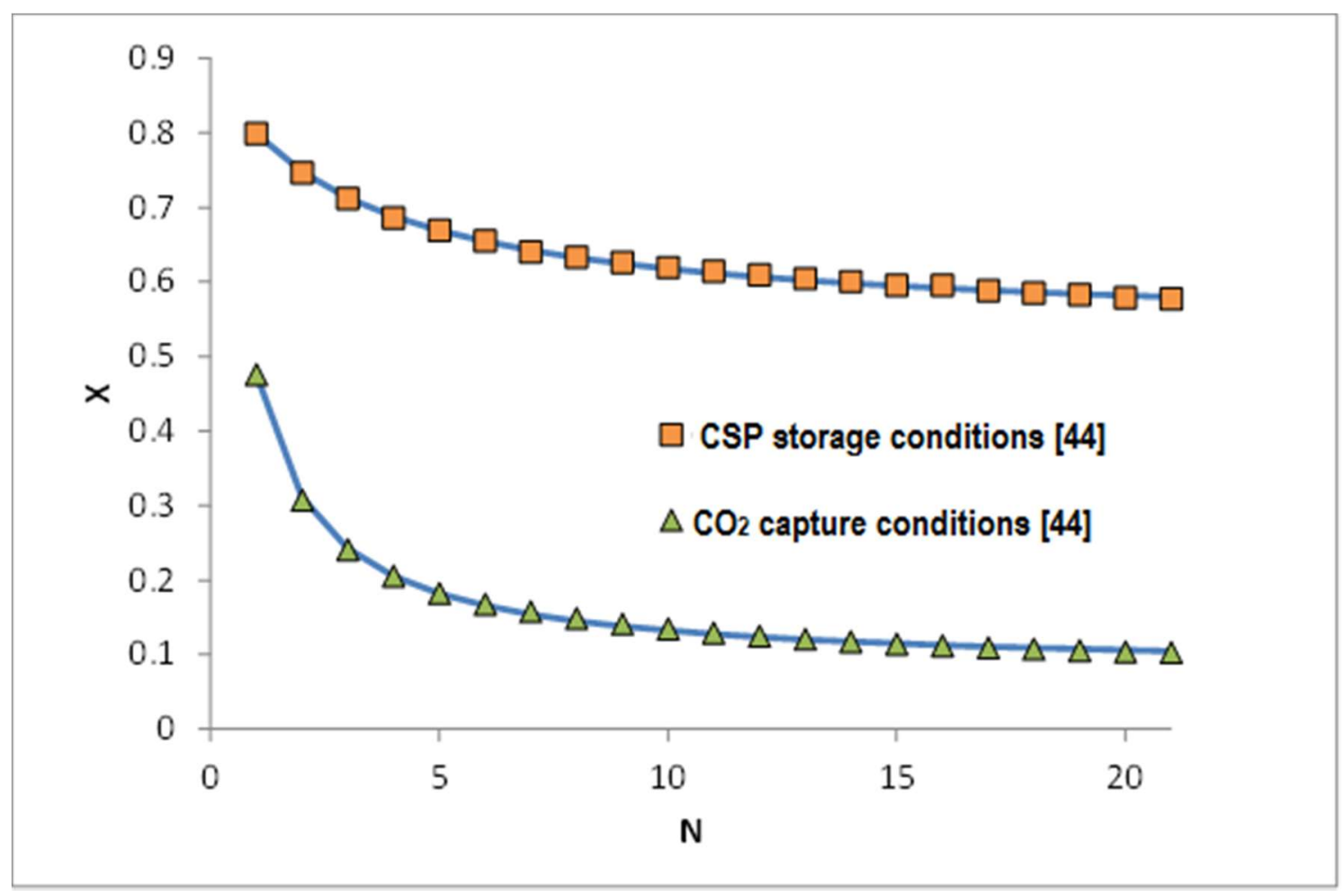

Figure 17: Multicycle conversion of limestone derived $\mathrm{CaO}$ as obtained from thermogravimetric analysis (TGA) tests under different CaL conditions (reported in [44]). CSP storage conditions: carbonation at $850 \circ \mathrm{C}$ under pure $\mathrm{CO}_{2}$ and calcination at 700 - $\mathrm{C}$ under pure $\mathrm{He}$. $\mathrm{CO}_{2}$ capture conditions: Carbonation at 650 - $\mathrm{C}$ under a $15 \% \mathrm{CO} 2 / 85 \%$ air vol/vol atmosphere and calcination at 950 -C under a $70 \% \mathrm{CO} / 30 \%$ air vol/vol atmosphere. Residence times at both stages were $5 \mathrm{~min}$. The solid lines are best fits from Eq. 10 to data. 

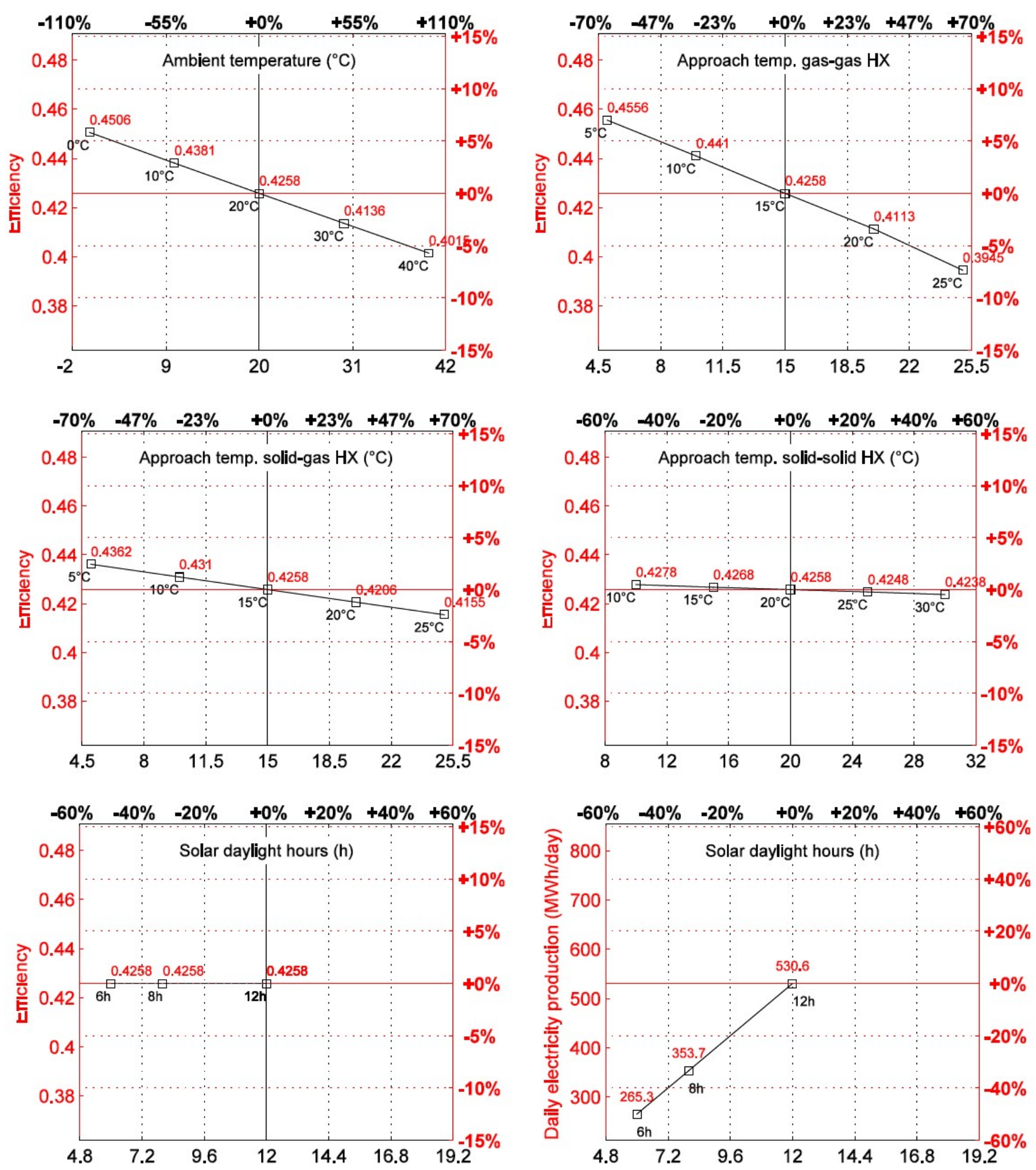

Figure 18: Efficiency variation derived from a sensitivity analysis on ambient temperature, heat exchangers and solar daylight hours using as reference values shown in iError! No se encuentra el origen de la referencia.. 

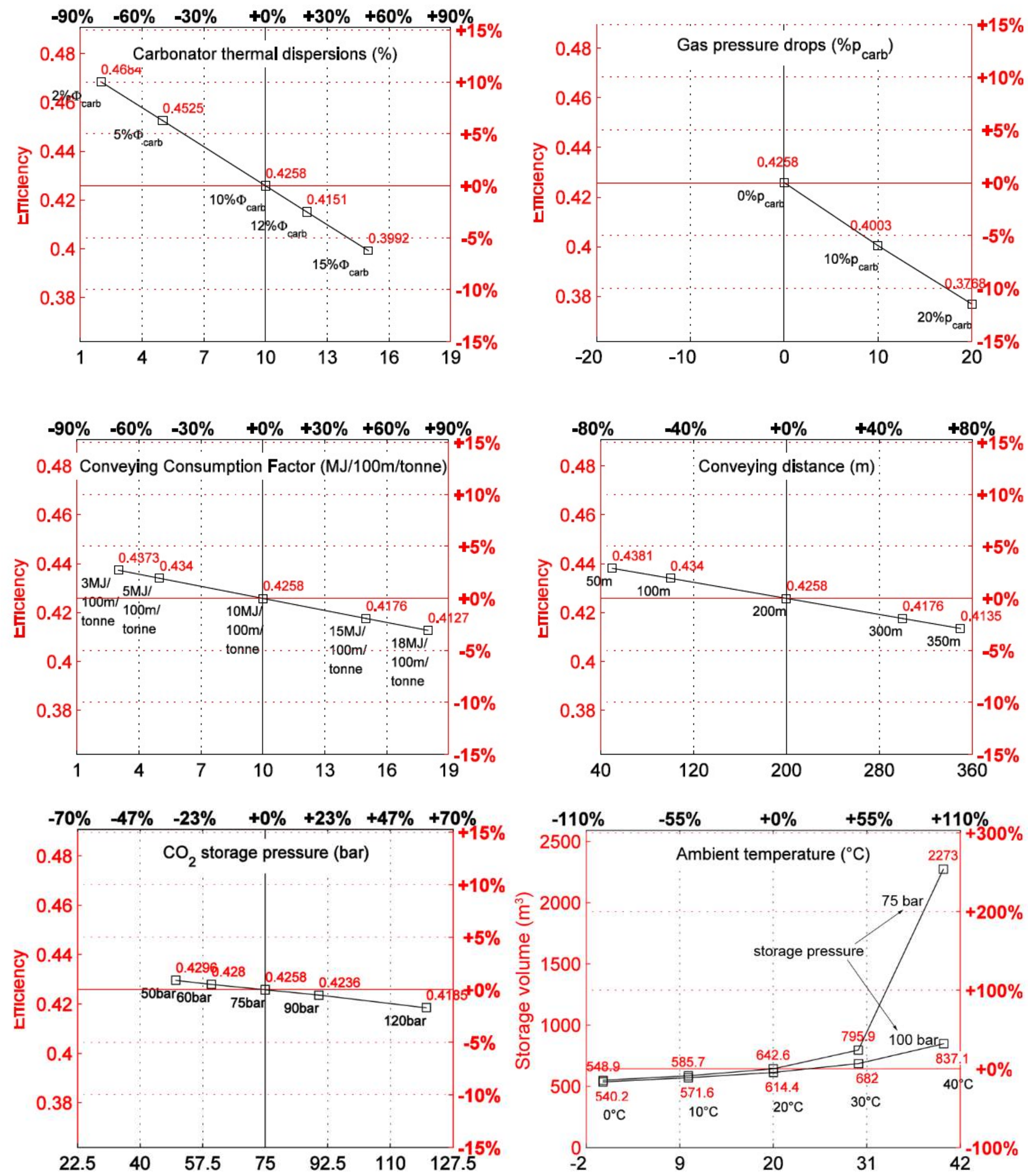

Figure 19: Efficiency variation derived from a sensitivity analysis on carbonator thermal dispersion, system transport and storage pressure using as reference values shown in iError! No se encuentra el origen de la referencia.. 
